\title{
Effects of Hydrophobic Modifications on the Solution Self-Assembly of P(DMAEMA-co-QDMAEMA)- $b$-POEGMA Random Diblock Copolymers
}

\author{
Martha Kafetzi and Stergios Pispas *(D)
}

check for updates

Citation: Kafetzi, M.; Pispas, S. Effects of Hydrophobic Modifications on the Solution Self-Assembly of P(DMAEMA-co-QDMAEMA)- $b$ POEGMA Random Diblock Copolymers. Polymers 2021, 13, 338 https://doi.org/10.3390/ polym13030338

Academic Editor: Ivan Gitsov

Received: 24 December 2020

Accepted: 19 January 2021

Published: 21 January 2021

Publisher's Note: MDPI stays neutral with regard to jurisdictional claims in published maps and institutional affiliations.

Copyright: (c) 2021 by the authors. Licensee MDPI, Basel, Switzerland. This article is an open access article distributed under the terms and conditions of the Creative Commons Attribution (CC BY) license (https:// creativecommons.org/licenses/by/ $4.0 /)$
Theoretical and Physical Chemistry Institute, National Hellenic Research Foundation, 48 Vassileos Constantinou Avenue, 11635 Athens, Greece; mkafetzi91@gmail.com

* Correspondence: pispas@eie.gr; Tel.: +30-210-727-3824

Abstract: In this work, the synthesis and the aqueous solution self-assembly behavior of novel partially hydrophobically modified poly(2-(dimethylamino) ethyl methacrylate)-b-poly(oligo(ethylelene glycol) methyl ether methacrylatetabel) $\mathrm{pH}$ and temperature responsive random diblock copolymers (P(DMAEMA-co- $\mathrm{Q}_{6 / 12}$ DMAEMA)- $b$-POEGMA), are reported. The chemical modifications were accomplished via quaternization with 1-iodohexane $\left(Q_{6}\right)$ and 1-iodododecane $\left(Q_{12}\right)$ and confirmed by ${ }^{1} \mathrm{H}$-NMR spectroscopy. The successful synthesis of PDMAEMA- $b$-POEGMA precursor block copolymers was conducted by RAFT polymerization. The partial chemical modification of the diblocks resulted in the permanent attachment of long alkyl chains on the amine groups of the PDMAEMA block and the presence of tertiary and quaternary amines randomly distributed within the PDMAEMA block. Light scattering techniques confirmed that the increased hydrophobic character results in the formation of nanoaggregates of high mass and tunable $\mathrm{pH}$ and temperature response. The characteristics of the aggregates are also affected by the aqueous solution preparation protocol, the nature of the quaternizing agent and the quaternization degree. The incorporation of long alkyl chains allowed the encapsulation of indomethacin within the amphiphilic diblock copolymer aggregates. Nanostructures of increased size were detected due to the encapsulation of indomethacin into the interior of the hydrophobic domains. Drug release studies demonstrated that almost $50 \%$ of the encapsulated drug can be released on demand by aid of ultrasonication.

Keywords: amphiphilic block copolymers; random blocks; RAFT polymerization; quaternization; hydrophobic modification; solution properties; $\mathrm{pH}$-response; temperature-induced response; encapsulation of indomethacin

\section{Introduction}

Amphiphilic block copolymers (AmBCs) have gained extensive scientific interest over the last decades in studies regarding the synthesis of novel materials, by employing facile polymerization techniques, along with the at-length apperception of their behavioral features allowing for their utilization in a broad field of applications [1,2]. The most fascinating feature of AmBCs is the formation of nanosized structures via self-assembly processes when inserted in aqueous media and thus their potential implementation in nanotechnology based concepts [3-5]. This impressive ability along with other capacities, such as the structural adjustment to surrounding media, the response to physicochemical stimuli and the interaction with biomolecules, ensures the eligibility of AmBCs for advanced biomedical applications, such as gene and drug delivery, and theranostics [6,7]. According to each application requirement, control over the structural and morphological features of the nanoparticulate structures may be imprinted during the synthesis process [3]. Molecular weight, composition and architecture are parameters of major importance for achieving nanostructures of specific morphology and function [3]. Random copolymers are an emerging class of synthetic polymeric materials that regained the interest of the 
scientific community only in recent years [8]. Progress in controlled radical polymerization methodologies brought the synthesis and investigation of the random copolymers to the forefront again as their molecular characteristics can be regulated in a considerable degree, taking also into account that random copolymers excel block copolymer in certain features $[9,10]$. Briefly, the incorporation of more than one functional monomeric unit can occur at one synthesis step and the supramolecular structures formed depend upon the molecular weight, the complexity of the system (number and nature of comonomers) and the functionality of the chosen comonomers [8-11]. Generally, random copolymers when inserted in aqueous media may self-fold intramolecularly into unimolecular micelle-like structures [9-11]. On the other hand, block copolymers more often self-assemble into coreshell type multichain micelles [12]. The hydrophobic/hydrophilic fraction of amphiphilic random copolymers plays the most significant role on their self-organization behavior. Considerably lower hydrophobic content results in intramolecular self-folding and formation of single chain nanoparticles with hydrophobic core domains consisted of the hydrophobic units $[10,11,13,14]$. When the hydrophobic content increases, intermolecular self-assembly occurs and multichain aggregates are formed [13-16].

Intelligent or stimuli-responsive polymers are an essential class of synthetic polymers that differ from conventional polymers because they are reactive to microenvironmental changes and as a result, they transit into a different physicochemical state, forming supramolecular nanostructures of diverse morphologies [2,17-20]. The interchange between hydrated and dehydrated state appoints them as interesting nanocarriers for gene and drug delivery applications $[18,21-26]$. These structural, physical or chemical alterations may be reversible or irreversible [27]. The introduction of stimuli-responsive polymeric units in a polymeric system enhances the system's functionality and structural intricacy at the molecular and supramolecular level [28]. The capability of amphiphilic stimuli-sensitive random and/or block copolymers to self-assemble can be handled after being subjected to one or more external stimuli such as temperature, $\mathrm{pH}$ and ionic strength $[25,29-33]$. Polymers exhibiting $\mathrm{pH}$ and temperature sensitivity are two classes of intriguing intelligent polymers due to their utilization in bioapplications [18]. Poly(2-(dimethylamino)ethyl methacrylate) (PDMAEMA) is a $\mathrm{pH}$ and temperature responsive polymer [34]. The transition to a more hydrophobic state from a hydrophilic one occurs at a lower critical solution temperature (LCST) of about $40-50{ }^{\circ} \mathrm{C}$ [35]. It is a weak polyelectrolyte of pKa ca. 7.4, comprising of basic segments, that behave as proton acceptors in response to changes in the environmental $\mathrm{pH}$ values [36]. PDMAEMA's cationic character along with its $\mathrm{pH}$ dependent hydration/dehydration characteristics, low cytotoxicity, high encapsulation capacity and low enough immunogenicity establish it as a promising vector for biomacromolecules delivery, such as nucleic acids and proteins, aiming at gene and protein delivery applications [37].

Reversible addition fragmentation chain transfer polymerization (RAFT) exhibits notable advantages in the synthesis of intelligent (smart) polymers, and random and block copolymers [38]. Firstly, it allows the synthesis of well-defined polymers of predetermined molecular characteristics [2,38-40]. Molecular weight and composition can be manipulated by fitting the polymerization conditions. Incorporation of a variety of monomers, multiplicity of molecular architectures, mild and manageable polymerization conditions, absence of catalysts to be removed after the end of polymerization and the potential for conducting the polymerization process in aqueous media are only a few beneficial features that RAFT polymerization provides $[38,41,42]$.

In this work, we report on the synthesis of poly(2-(dimethylamino) ethyl methacrylate)b-poly((oligo ethylene glycol methyl ether methacrylate) (PDMAEMA-b-POEGMA) double hydrophilic diblock copolymers by utilizing sequential RAFT polymerization [43] and their subsequent partial hydrophobic chemical modification by quaternization reaction with iodohexane and iodododecane to produce novel P(DMAEMA-co-Q ${ }_{6}$ DMAEMA)- $b$ POEGMA and P(DMAEMA-co-Q ${ }_{12}$ DMAEMA)- $b$-POEGMA random diblock copolymers, respectively $\left(Q_{6}\right.$ and $Q_{12}$ prefixes present the number of carbon atoms that the attached 
alkyl chain on the PDMAEMA groups bears). The result of the partial chemical modifications is the construction of novel diblock copolymers where the first block contains hydrophilic and hydrophobic monomeric units that are distributed in a random fashion. The amine groups of the PDMAEMA block were partially modified with iodohexane or iodododecane in a predetermined percentage, in order to attach positive charges in some amine side groups [44-46] for subsequent bioapplications, and at the same time introduce long alkyl chains that will amplify the hydrophobic character of the polymeric system [44]. The DMAEMA monomer was chosen bearing in mind its responsiveness to $\mathrm{pH}$ and temperature changes, as well as its potential application to nanomedical fields. The OEGMA monomer was included due to ameliorated solubility and colloidal stability that oligo ethylene glycol side chains introduce, as well as the biocompatibility and low-cytotoxicity it exhibits [47]. The quaternization of the tertiary amine groups of PDMAEMA, using long alkyl halides as the quaternization factors to fabricate permanent cationic units along the polymer chain, has been investigated in a limited number of cases $[44,48,49]$, while quaternization of PDMAEMA using methyl iodide $\left(\mathrm{CH}_{3} \mathrm{I}\right)$ is more intensively studied [50-53]. Cationic polymers are important in a wide range of applications such as antifouling, and drug, gene and protein delivery [54]. In particular, Koufakis et al. reported on the synthesis of cationic polymeric brushes which display bactericidal character against both Gram-positive and Gram-negative bacteria strains when alkyl chains of less than six carbons atoms are grafted [49]. The PDMAEMA block was chosen not to be completely quaternized in order to maintain some $\mathrm{pH}$ and temperature responsiveness, while the incorporation of long alkyl chains will allegedly influence the response of all obtained modified random diblock copolymers to both stimuli $[44,55]$. Therefore, the self-assembly behavior of the partially quaternized random diblock copolymers was investigated upon heating and at varying $\mathrm{pH}$ of their aqueous solutions. The ameliorated hydrophobic character of the obtained partially quaternized random diblock copolymers established by the attachment of the long alkyl chains, establishes them also as potential nanocarriers for hydrophobic drugs. Thereupon the interactions of the quaternized random diblock copolymers with indomethacin and the resulting drug loaded nanoparticles were investigated with light scattering techniques (DLS, SLS, ELS) and infrared spectroscopy (ATR-FTIR). Indomethacin is a hydrophobic, anti-inflammatory drug commonly prescribed to diminish physical symptoms such as fever, ache, stiffness, and swelling from inflammation [56]. The pharmaceutical substance is expected to be encapsulated into the internal hydrophobic domains of the diblock nanostructures. The loading efficiency was determined by utilizing UV-Visible spectroscopy (UV-Vis), while release studies were conducted by applying ultrasound, demonstrating the on demand release of the drug.

\section{Materials and Methods}

\subsection{Materials}

Monomers 2-(dimethylamino)ethyl methacrylate (DMAEMA, 98\%) and (oligo ethylene glycol)methacrylate (OEGMA) (average $\mathrm{M}_{\mathrm{n}}=475 \mathrm{~g} / \mathrm{mol}$, 9 ethylene oxide units) were purchased from Sigma Aldrich, Athens, Greece. Monomers were purified by passing through a column packed with inhibitor removers before polymerization. 2,2'-Azobis (isobutyronitrile) (AIBN) was purified by recrystallization from methanol. 4-Cyano-4[(dodecylsulfanylthiocarbonyl)sulfanyl]pentanoic acid (CPD) as the CTA, 1-iodohexane $\left(\mathrm{C}_{6} \mathrm{H}_{13} \mathrm{I} . \geq 98 \%\right)$, 1-iodododecane $\left(\mathrm{C}_{12} \mathrm{H}_{25} \mathrm{I}, 98 \%\right)$ 1,4-dioxane ( $\geq 99.8 \%$ pure), which was dried over molecular sieves before use, tetrahydrofuran (THF, $\geq 99.9 \%$ pure), and $\mathrm{n}$-hexane $(\geq 97 \%)$ were also purchased from Sigma Aldrich, Athens, Greece. Indomethacin (IND) was obtained from Fluka, Athens, Greece and used as received. Experimental details on the diblock copolymer synthesis are provided in the Supplementary Materials section. 
2.2. Self-Assembly of the Partially Chemically Modified

$P\left(D M A E M A-c o-Q_{6} D M A E M A\right)-b-P O E G M A$ and

$P\left(D M A E M A-c o-Q_{12} D M A E M A\right)-b-P O E G M A$ Random Diblock Copolymers

The synthetic process of the PDMAEMA- $b$-POEGMA diblock copolymers and the partial quaternization of the PDMAEMA block in order to produce P(DMAEMA-co$\mathrm{Q}_{6 / 12}$ DMAEMA)- $b$-POEGMA random diblock copolymers is described in detail in the Supplementary Materials. Two protocols were followed in order to prepare stock solutions of the partially hydrophobically modified random diblock copolymers. The first one involves the direct dissolution of dry solid copolymers in distilled water. The second one concerns the initial dissolution of the dry solids in THF, the addition of the mixture in distilled water and then the evaporation of the organic solvent. Specifically, the first protocol includes the addition of the appropriate volume of distilled water of $\mathrm{pH} 7$, in a specific quantity of copolymer's dry solid. The resulted mixture remained for two hours at room temperature, then was heated up to $60{ }^{\circ} \mathrm{C}$ for three hours under stirring and then heating continued overnight up to $60^{\circ} \mathrm{C}$ in an oven. Afterwards, the solution was left overnight at room temperature and studied the following day in order to be in thermodynamic equilibrium. By implementing this protocol, samples of concentration $5 \times 10^{-3} \mathrm{~g} / \mathrm{mL}(10 \mathrm{~mL}$ of water of $\mathrm{pH} 7$ were placed in a vial containing $50 \mathrm{mg}$ of dry solid) and $1 \times 10^{-3} \mathrm{~g} / \mathrm{mL}$ were prepared. The second protocol involves the dissolution of $10 \mathrm{mg}$ of dry copolymer in $2 \mathrm{~mL}$ of THF and subsequently the injection of the resulted solution in distilled water of $\mathrm{pH} 7$, under vigorous stirring. After two minutes of stirring, the latter mixture was heated until THF was evaporated and the final aqueous solution of $1 \times 10^{-3} \mathrm{~g} / \mathrm{mL}$ concentration was obtained. The final solution was kept at room temperature overnight and studied the following day. The $\mathrm{pH}$ studies were held by carrying out the same preparation process, regardless of the protocol that was followed in order to prepare the aqueous solutions. The variable $\mathrm{pH}$ protocol that was followed is described in the following. The next day a certain volume of each aqueous stock solution was taken in order to regulate the $\mathrm{pH}$ of the resulting solutions. $10 \mu \mathrm{L}$ of $0.1 \mathrm{M} \mathrm{HCl}$ was added in order to tune the $\mathrm{pH}$ of the aqueous solution of $\mathrm{c}=1 \times 10^{-3} \mathrm{~g} / \mathrm{mL}$ at $\mathrm{pH} 3$, while $50 \mu \mathrm{L}$ of $0.1 \mathrm{M} \mathrm{HCl}$ was added in order to tune the $\mathrm{pH}$ of the aqueous solution of $\mathrm{c}=5 \times 10^{-3} \mathrm{~g} / \mathrm{mL}$ at $\mathrm{pH}$. $50 \mu \mathrm{L}$ of $0.1 \mathrm{M} \mathrm{NaOH}$ to tune the solution of $\mathrm{c}=1 \times 10^{-3} \mathrm{~g} / \mathrm{mL}$ at $\mathrm{pH} 10$ and $50 \mu \mathrm{L}$ of $0.1 \mathrm{M}$ $\mathrm{NaOH}$ to tune the solution of $\mathrm{c}=5 \times 10^{-3} \mathrm{~g} / \mathrm{mL}$ at $\mathrm{pH} 10$. The final solutions where the $\mathrm{pH}$ was regulated at 3 and 10, respectively, were left for $2 \mathrm{~h}$ before conducting the measurements, in order to achieve equilibrium. Light scattering techniques (dynamic light scattering/DLS, static light scattering/SLS and electrophoretic light scattering/ELS) were used to study the properties of all aqueous copolymer solutions. The aqueous solutions of the more hydrophobic derivatives of the PDMAEMA PD- $_{42}-\mathrm{POEGMA}_{12}$ precursor diblock were prepared only by using the organic solvent protocol (see Supplementary Materials).

\subsection{Interaction Studies of $P\left(D M A E M A-c o-Q_{6} D M A E M A\right)-b-P O E G M A$ and $P\left(D M A E M A-c o-Q_{12} D M A E M A\right)-b-P O E G M A$ Random Diblock Copolymers with Indomethacin (IND)}

\subsubsection{Indomethacin (IND) Loading Studies}

Mixed nanoaggregates of the random diblock copolymers with indomethacin were prepared by using the following process. At first IND solutions and $\mathrm{Q}_{6}, \mathrm{Q}_{12}$ modified diblocks of quaternization degree $50 \%$ in THF $\left(5 \times 10^{-3} \mathrm{~g} / \mathrm{mL}\right)$ were prepared. The IND concentration in THF was calculated according to the targeted encapsulated drug amount. The intended IND encapsulation degrees were 10 and $20 \%$ based on the total mass of the diblock utilized in each time. Subsequently, the two solutions were mixed in appropriate ratios, to vary the IND/copolymer mass ratio and the mixtures were injected fast in distilled water of $\mathrm{pH} 7$ that was vigorously stirred. The latter mixture was heated until THF was evaporated and mixed IND/P(DMAEMA-co-Q ${ }_{6 / 12}$ DMAEMA)- $b$-POEGMA solutions of final concentration of $1 \times 10^{-3} \mathrm{~g} / \mathrm{mL}$ were obtained. The mixed solutions were investigated by light scattering techniques. The IND loading efficiency was determined with the assistance of a calibration curve of IND in THF by a Perkin-Elmer, Lambda 19 spectropho- 
tometer, USA at $\lambda_{\max }=318 \mathrm{~nm}$. The interactions between IND and partially quaternized samples were studied via ATR-FTIR spectroscopy (Bruker Optik, Ettlingen, Germany).

\subsubsection{IND Release Studies}

The polymeric aggregates with the encapsulated IND were placed in dialysis bags of $3.5 \mathrm{kDa}$ MWDO. Specifically, $10 \mathrm{~mL}$ of solution were added in the dialysis bag which was placed in $100 \mathrm{~mL}$ of water for injection and then put in a SOLTEC, SONICA 3300ETH-S3 ultrasonic bath. Amounts of the external aqueous solution were taken in defined time intervals and each time the aqueous solution was restored to its initial volume, so that the reservoir conditions remain constant. The IND percentage that was released at different time intervals, until $4 \mathrm{~h}$, was assessed with the aid of a calibration curve of IND in THF by a Perkin-Elmer, Lambda 19 spectrophotometer, at $\lambda_{\max }=318 \mathrm{~nm}$. Initial studies conducted without the use of sonication bath indicated that IND could not be released from the aggregates in a period of $12 \mathrm{~h}$.

\subsection{Characterization Methods}

A Waters size exclusion chromatography (SEC) instrument from Waters Technologies Corporation, Caguas, Puerto Rico, was utilized for the determination of the molecular weights and the molecular weight distributions of the synthesized PDMAEMA homopolymers and PDMAEMA- $b$-POEGMA precursor diblock copolymers. It was equipped with a Waters 1515 isocratic pump, a set of three $\mu$-Styragel mixed bed columns (pore diameter between $10^{2}$ and $10^{6} \AA$ ) and a Waters 2414 refractive index (equilibrated at $40^{\circ} \mathrm{C}$ ). Breeze software was used for data acquisition and analysis. THF (containing $5 \% v / v$ triethylamine) comprised the mobile phase, at a flow rate of $1.0 \mathrm{~mL} / \mathrm{min}$, at $30^{\circ} \mathrm{C}$. Polystyrene standards of average molecular weights between 1200 and 152,000 g/mol and narrow molecular weight distributions were utilized for the calibration of the SEC set-up. In order to determine the molecular weights and the molecular weight distributions, the polymers were dissolved in THF at a concentration of $1 \times 10^{-3} \mathrm{~g} / \mathrm{mL}$.

${ }^{1} \mathrm{H}-\mathrm{NMR}$ experiments were conducted on a Varian $300(600 \mathrm{MHz})$ spectrometer using Vjnmr software obtained from Scientific instruments, Palo Alto, California and tetramethylsilane (TMS) used as the internal standard in $\mathrm{D}_{2} \mathrm{O}$. The chemical shifts are reported in the following.

A BI-DNDC Differential Refractometer from Brookhaven instruments Holtsville, New York, NY, United States was utilized for the determination of the $\mathrm{dn} / \mathrm{dc}$ of the P(DMAEMA-co-Q ${ }_{6}$ DMAEMA)-b-POEGMA and P(DMAEMA-co-Q 6 DMAEMA)- $b$-POEGMA random diblock copolymers, in solutions. The instrument calibration was conducted by measuring aqueous solutions of $\mathrm{KCl}$ at specific concentrations.

Dynamic light scattering (DLS) experiments were conducted on an ALV/CGS-3 compact goniometer system (ALV GmbH), composed of an ALV 5000/EPP multi- $\tau$ digital correlator with 288 channels and an ALV/SE-5003 light scattering electronics unit for stepper motor drive and limit switch control. A JDS Uniphase $22 \mathrm{~mW}$ He-Ne laser $(\lambda=632.8 \mathrm{~nm})$ was utilized as the light source. All obtained by ALV GmbH, Langen (Hessen), Germany. Autocorrelation functions were analyzed by the cumulants method [57] and the CONTIN algorithm [58]. Before measurements, dust particles were removed from the solutions by filtration through $0.45 \mathrm{~mm}$ hydrophilic PVDF filters. The samples were put into $1 \mathrm{~cm}$ width quartz cells and measurements were carried out within the angular range of $30-150^{\circ}$. A Polyscience model 9102 bath, purchased from Polyscience, Illinois, USA, equipped with a circulator was used in order to regulate temperature inside the measuring cell. Measurements were conducted in the temperature range of $25^{\circ} \mathrm{C}$ to $60^{\circ} \mathrm{C}$, in $5^{\circ} \mathrm{C}$ steps. Static light scattering (SLS) experiments were conducted on the same instrument at angles $30-150^{\circ}$ and from $25^{\circ} \mathrm{C}$ to $55^{\circ} \mathrm{C}$ temperature range. Toluene was used as the calibration standard. The $\mathrm{R}_{\mathrm{g}} / \mathrm{R}_{\mathrm{h} 0}$ ratios were calculated by implementing the Guinier method to light scattering data. 
Electrophoretic light scattering (ELS) studies were carried out on a ZetaSizer Nano series Nano ZS (Malvern Instruments Ltd., Malvern, United Kingdom), composed of a He-Ne laser at a wavelength of $633 \mathrm{~nm}$ and a fixed backscattering angle of $173^{\circ}$. The Henry approximation of the Smoluchowski equation [59] was used to analyze the obtained data, after equilibration of the polymer solutions at $25^{\circ} \mathrm{C}$ and $50{ }^{\circ} \mathrm{C}$. The recorded zeta-potential values are averages of 100 scans.

Optical absorption spectra of the P(DMAEMA-co-Q ${ }_{6}$ DMAEMA)-b-POEGMA/IND and P(DMAEMA-co- $\mathrm{Q}_{12}$ DMAEMA)- $b$-POEGMA/IND mixed solutions, IND solutions in THF and aqueous solutions of the released IND, were recorded on a Perkin-Elmer, Lambda 19 UV-Vis-NIR spectrophotometer, obtained from PerkinElmer Inc., USA. The measurements were carried out in the range of $200-450 \mathrm{~nm}$.

ATR-FTIR measurements were conducted at room temperature in the spectral range 5000 to $500 \mathrm{~cm}^{-1}$ on a Bruker Equinox 55 Fourier transform instrument (Bruker Optik, Ettlingen, Germany), utilizing a single bounce attenuated total reflectance (ATR) diamond accessory (Dura-Samp1IR II by SensIR Technologies, Chapel Hill, North California). Background spectra were obtained by recording the clean and dry ATR diamond crystal surface against air and then subtracted from the sample spectrum. PDMAEMA ${ }_{56}-b-$ POEGMA $_{86}$

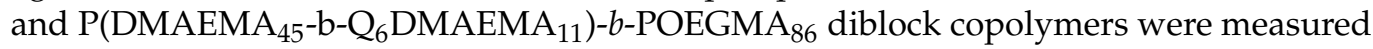
at their solid state, after the purification process was completed, in order to confirm the modified chemical structure of the diblock copolymer precursor was accomplished. In order to detect any interactions between the random diblock copolymers with IND, the aqueous solutions of the random diblock copolymers and the mixed nanoassemblies with IND were used. In these cases, water was evaporated by utilizing nitrogen so that the water absorption peaks would not intervene with the peaks that would show the interactions between IND and the random diblock copolymers. Afterwards, solid IND was measured in order to assign the presence of the new peaks at the ATR spectra of the mixed nanossemblies to the characteristic functional groups of IND. Additionally, 64 interferograms were collected for every single spectrum with a resolution of $4 \mathrm{~cm}^{-1}$ to attain the better signal/noise ratio.

\section{Results and Discussion}

3.1. Synthesis of $P\left(D M A E M A-c o-Q_{6 / 12} D M A E M A\right)-b-P O E G M A$ Chemically Modified Random Diblock Copolymers

Double hydrophilic, $\mathrm{pH}$ and temperature responsive $\mathrm{PDMAEMA}_{56}-b-\mathrm{POEGMA}_{86}$ and PDMAEMA 42 - $b$-POEGMA 12 were successfully synthesized by sequential RAFT polymerization. The combination of monomers towards synthesis of block copolymers via RAFT has been reported before [43]. PDMAEMA 56 and PDMAEMA 42 homopolymers were utilized as the macro-CTAs for the synthesis of PDMAEMA PD- $_{5-}-$ POEGMA $_{86}$ and PDMAEMA $_{42}-b$-POEGMA 12 diblock copolymers respectively. The synthetic process is depicted in Scheme 1. CPD was chosen as the CTA based on its compatibility with these type of monomers provided by studies performed at our lab [52]. SEC measurements were made after each polymerization step to determine the successful polymerization of each block, the molecular weights and molecular weight distributions of PDMAEMA homopolymers and their resulting diblock copolymers. As it can be observed in Figure 1, where SEC chromatograms of the PDMAEMA ${ }_{56}$ and the resulted PDMAEMA ${ }_{56}-b-$ POEGMA $_{86}$ are depicted, the molecular weight is increased after the incorporation of the POEGMA block, which is confirmed by the shift of the molecular weight distribution to lower elution volumes. Overall, SEC chromatograms (Figure 1) revealed the efficiency of the synthetic procedure followed and resulted in the formation of rather well-defined PDMAEMA ${ }_{56}-$ $b$-POEGMA $A_{86}$. The molecular weight distribution is adequately narrow and relatively symmetrical, even though a small tail exists indicating the almost complete re-initiation and consumption of the OEGMA units for producing the POEGMA block. Similar conclusions are extracted from the SEC chromatograms of PDMAEMA $42-b$-POEGMA 12 diblock copolymer. Molecular weights and polydispersity indexes of all synthesized polymers are presented in Table 1. The molecular weight distributions is in accordance with the principles of RAFT polymerization. 


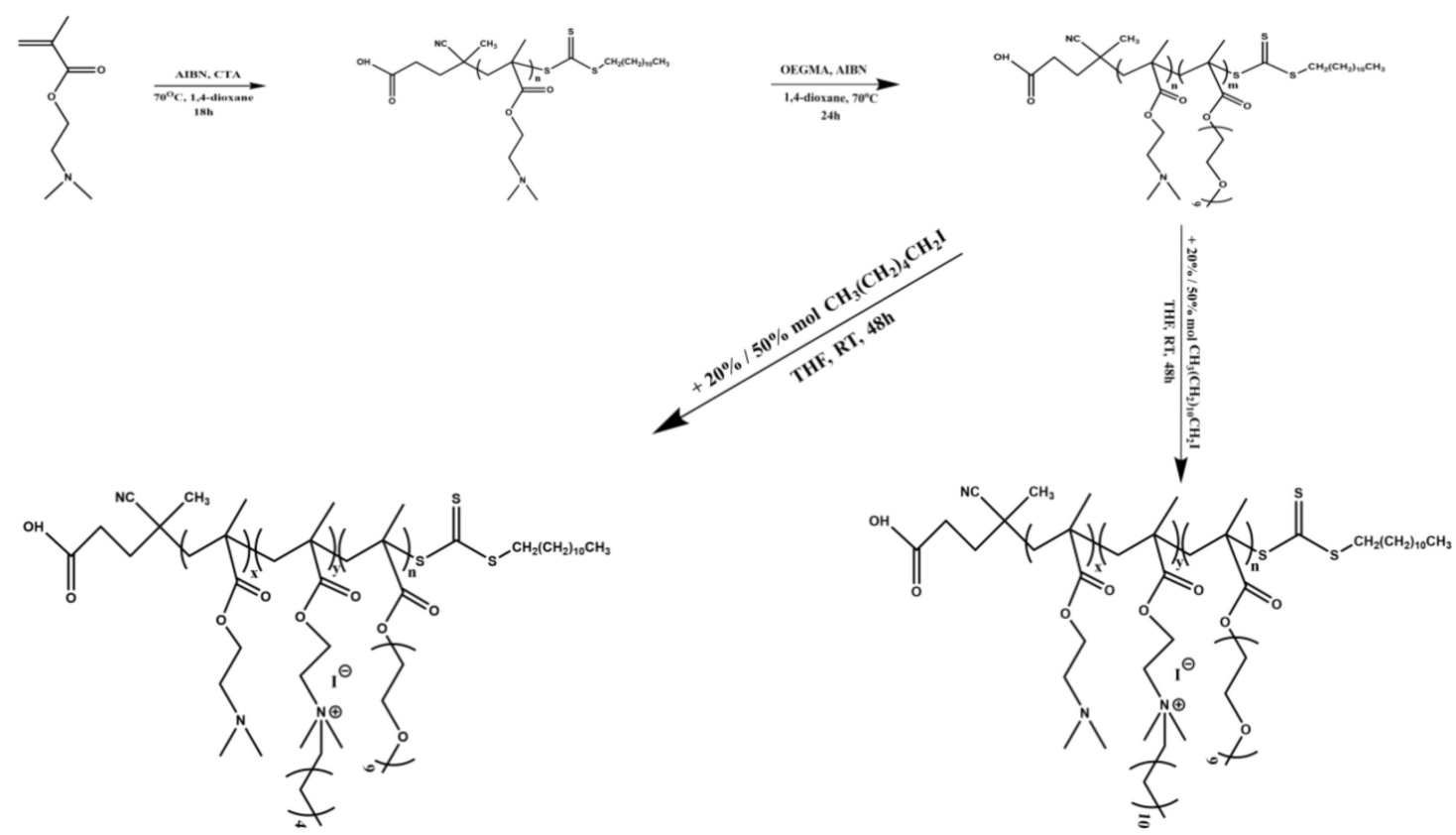

Scheme 1. Synthesis route to partially chemically modified P(DMAEMA-co-Q 6 DMAEMA)- $b$-POEGMA and P(DMAEMAco-Q ${ }_{12}$ DMAEMA)- $b$-POEGMA random diblock copolymers, via quaternization reactions of the PDMAEMA- $b$-POEGMA precursors, that were synthesized by RAFT, using iodohexane and iodododecane in different molar ratios.

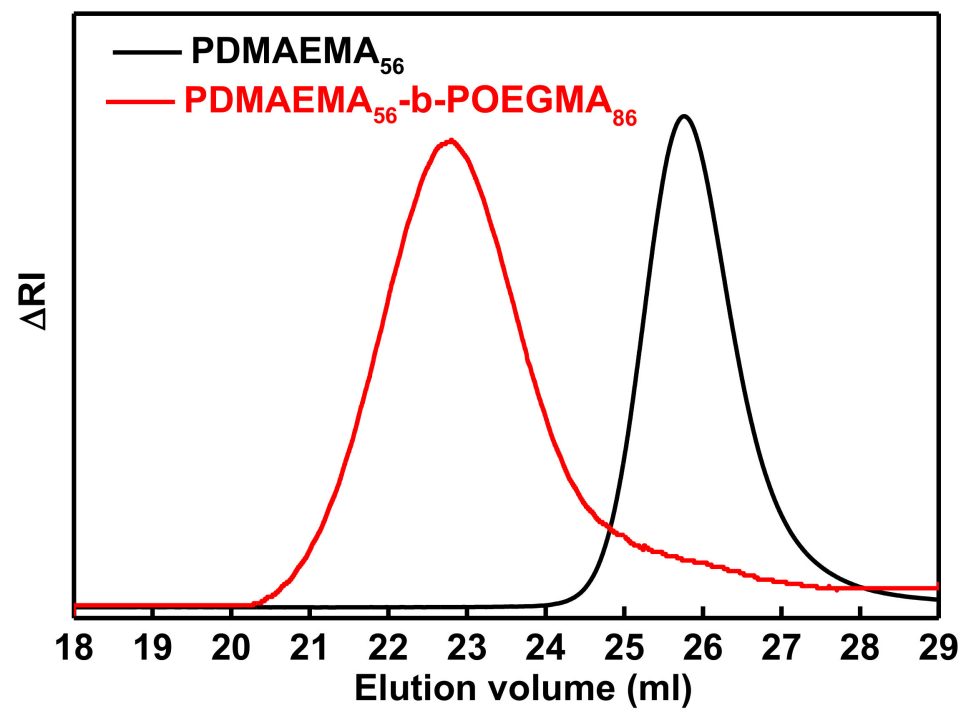

Figure 1. SEC chromatograms of PDMAEMA 56 (first block) and PDMAEMA ${ }_{56}-b-$ POEGMA $_{86}$ (final diblock copolymer).

The molecular characteristics of both PDMAEMA- $b$-POEGMA diblock copolymers are presented in Table $1 .{ }^{1} \mathrm{H}-\mathrm{NMR}$ comparative spectra of the PDMAEMA 42 and PDMAEMA $42^{-}$ $b$-POEGMA 12 can be found in SI (Figure S2). 
Table 1. Molecular characteristics of partially chemically modified P(DMAEMA-co-Q $6 / 12$ DMAEMA)- $b$-POEGMA random diblock copolymers and their precursors.

\begin{tabular}{|c|c|c|c|c|c|c|c|}
\hline Sample & $\begin{array}{l}\mathrm{M}_{\mathrm{W}} \mathrm{a}^{\mathrm{a}} \\
\left(\times 10^{4}\right) \\
(\mathrm{g} / \mathrm{mol})\end{array}$ & $\mathbf{M}_{\mathrm{W}} / \mathrm{Mn}^{\mathrm{a}}$ & $\begin{array}{c}\text { M }_{\text {wQDMAEMA }^{a}} \\
\left(\times 10^{4}\right) \\
(\mathrm{g} / \mathrm{mol})\end{array}$ & $\begin{array}{c}\% w t \\
\text { PDMAEMA }^{b}\end{array}$ & POEGMA $^{\text {b }}$ & $\begin{array}{c}\text { \%wt } \\
\text { QDMAEMA }^{a}\end{array}$ & $\begin{array}{l}\text { Quaternization } \\
\text { Degree (\%) }{ }^{b}\end{array}$ \\
\hline PDMAEMA $_{56}$ & 0.9 & 1.13 & - & 100 & - & - & - \\
\hline $\begin{array}{l}\text { PDMAEMA }_{56}-b- \\
\text { POEGMA }_{86}\end{array}$ & 4.95 & 1.4 & - & 16 & 82 & - & - \\
\hline $\begin{array}{l}\mathrm{P}\left(\mathrm{DMAEMA}_{45}-\mathrm{co}-\right. \\
\left.\mathrm{Q}_{6} \text { DMAEMA }_{11}\right)-b- \\
\text { POEGMA }_{86}\end{array}$ & $5.2^{\mathrm{c}}$ & - & 0.4 & 14 & 78 & 8 & 19 \\
\hline $\begin{array}{l}\mathrm{P}\left(\mathrm{DMAEMA}_{30}-\mathrm{co}-\right. \\
\left.\mathrm{Q}_{6} \text { DMAEMA }_{26}\right)-b- \\
\text { POEGMA }_{86}\end{array}$ & $5.5^{c}$ & - & 1.0 & 9 & 74 & 17 & 46 \\
\hline $\begin{array}{c}\mathrm{P}\left(\mathrm{DMAEMA}_{44-\mathrm{co}}\right. \\
\left.\mathrm{Q}_{12} \mathrm{DMAEMA}_{12}\right)^{-} \\
b \text {-POEGMA } \\
\end{array}$ & $5.3^{c}$ & - & 0.55 & 13 & 77 & 10 & 20 \\
\hline $\begin{array}{c}\mathrm{P}\left(\mathrm{DMAEMA}_{28}-\mathrm{co}-\right. \\
\left.\mathrm{Q}_{12} \mathrm{DMAEMA}_{28}\right)^{-} \\
b \text {-POEGMA } \\
\end{array}$ & $5.8^{c}$ & - & 1.3 & 7 & 71 & 22 & 50 \\
\hline PDMAEMA $_{42}$ & 0.65 & 1.15 & - & 100 & - & - & - \\
\hline $\begin{array}{l}\text { PDMAEMA }_{42}-b- \\
\text { POEGMA }_{12}\end{array}$ & 1.2 & 1.4 & - & 55 & 45 & - & - \\
\hline $\begin{array}{l}\mathrm{P}\left(\mathrm{DMAEMA}_{34} \text {-co- }\right. \\
\left.\mathrm{Q}_{6} \text { DMAEMA }_{8}\right)-b- \\
\text { POEGMA }_{12}\end{array}$ & $1.4^{\mathrm{c}}$ & - & 0.3 & 39 & 39 & 22 & 19 \\
\hline $\begin{array}{l}\mathrm{P}\left(\mathrm{DMAEMA}_{22}-\mathrm{CO}-\right. \\
\left.\mathrm{Q}_{6} \mathrm{DMAEMA}_{20}\right)-b- \\
\text { POEGMA }_{12}\end{array}$ & $1.6^{c}$ & - & 0.75 & 21 & 33 & 46 & 48 \\
\hline $\begin{array}{l}\mathrm{P}\left(\mathrm{DMAEMA}_{33}-\mathrm{co}-\right. \\
\left.\mathrm{Q}_{12} \text { DMAEMA }_{9}\right)-b- \\
\text { POEGMA }_{12}\end{array}$ & $1.5^{c}$ & - & 0.4 & 36 & 36 & 28 & 20 \\
\hline $\begin{array}{l}\text { P(DMAEMA }{ }_{21} \text {-co- } \\
\left.\text { Q }_{12} \text { DMAEMA }_{21}\right)^{-} \\
b \text {-POEGMA } \\
12\end{array}$ & $1.8^{c}$ & - & 1.0 & 18 & 29 & 53 & 50 \\
\hline
\end{tabular}

${ }^{a}$ Determined by SEC in THF, containing $5 \%$ trimethylamine in $\mathrm{THF},{ }^{\mathrm{b}}$ Determined by ${ }^{1} \mathrm{H}-\mathrm{NMR},{ }^{\mathrm{c}}$ Determined by SLS in THF. Note: Values of the weight fractions and the quaternization degrees were determined with standard deviations of $\pm 1 \%$.

Post-polymerization partial quaternization of the DMAEMA segments of the PDMAEMA$b$-POEGMA precursors was achieved towards production of novel chemically modified P(DMAEMA-co-Q ${ }_{6}$ DMAEMA)- $b$-POEGMA and P(DMAEMA-co- ${ }_{12}$ DMAEMA)-bPOEGMA random diblock copolymers by using two alkyl halides of different alkyl chain length. By implementing partial quaternization of DMAEMA segments, only part of the tertiary amine groups of DMAEMA are converted into their quaternary analogues. Consequently, the synthesis of novel amphiphilic random diblock copolymers was accomplished by the method described above. PDMAEMA a weak cationic polyelectrolyte that after quaternization process takes place it transforms into a partially strong cationic polyelectrolyte [44]. This conversion is of great importance as a number of cationic charges, defined by the quaternization degree, are permanently present onto the amine groups and are randomly distributed along the modified block. Moreover, the presence of cationic groups allows the utilization of the present copolymers in gene delivery applications and increases the antifouling ability of the copolymers [49]. By modifying only part of the total amount of amino groups, responsiveness of the diblocks to $\mathrm{pH}$ and temperature variations is expected to be altered but not to be completely absent $[46,60]$. The addition of long alkyl chains of different lengths is another interesting characteristic that is worth investigating as they impart amphiphilic character to the random diblock and as a result, they affect the self-assembly properties [44]. In addition, the presence of long hydrophobic groups should 
affect the $\mathrm{pH}$ and temperature-induced behavior of the formed nanoassemblies. It should be noted that the existence of POEGMA block would assist in surpassing solubility obstacles and provide colloidal stability in the aqueous solutions of the partially quaternized diblock copolymers, as well as increased biocompatibility. The effect of the POEGMA composition on the self-organization behavior of the nanostructures is investigated below by light scattering techniques. PDMAEMA- $b$-POEGMA precursors were modified at 20 and $50 \%$ molar ratio using 1-iodohexane $7\left(\mathrm{C}_{6} \mathrm{H}_{13} \mathrm{I}\right)$ and 1-iodododecane $\left(\mathrm{C}_{12} \mathrm{H}_{25} \mathrm{I}\right)$ $\left(\mathrm{C}_{6} \mathrm{H}_{12} \mathrm{I}\right.$ moles / PDMAEMA moles $=0.2$ and $0.5, \mathrm{C}_{12} \mathrm{H}_{25} \mathrm{I}$ moles $/$ PDMAEMA moles $=0.2$ and 0.5$)$. Specifically, by partial quaternization of the PDMAEMA ${ }_{56}-b-$ POEGMA $_{86}$ precursor four different chemically modified diblock copolymers were obtained, two with alkyl hydrophobic chains of six carbons atoms and two with alkyl hydrophobic chains of twelve carbon atoms. The two copolymers containing alkyl hydrophobic chains of the same carbon atoms differ in the number of the alkyl chains attached to the amine groups of the DMAEMA residues, i.e., in the degree of quaternization. The same scheme was followed for the partial quaternization of PDMAEMA ${ }_{42}-b$-POEGMA 12 precursor diblock. In summary, eight novel partially hydrophobically modified diblock copolymers were obtained, that differ in their molecular characteristics.

Figure 2a displays the ${ }^{1} \mathrm{H}-\mathrm{NMR}$ spectrum for the P(DMAEMA-co- ${ }_{6}$ DMAEMA)$b$-POEGMA random diblock copolymer that derived from the partial quaternization of PDMAEMA $_{42}-b$-POEGMA 12 , at nominal degree of quaternization $50 \%$ using 1-iodohexane. The characteristic spectral peaks of both the DMAEMA and $\mathrm{Q}_{6}$ DMAEMA segments are observed at $2.42 \mathrm{ppm}\left(-\mathrm{NH}\left(\mathrm{CH}_{3}\right)_{2}-\right)$ and $3.35 \mathrm{ppm}\left(-\mathrm{N}^{+}\left(\left(\mathrm{CH}_{3}\right)_{2}\left(\mathrm{CH}_{2}\right)\right)-\right)$ respectively. The degree of quaternization of the diblock copolymer was estimated by determining the integrals of the peaks at $2.42 \mathrm{ppm}$ and at $3.35 \mathrm{ppm}$, which correspond to the $-\mathrm{CH}_{3}$ protons of the tertiary amines of the DMAEMA residues and the $-\mathrm{CH}_{3}$ protons attached to the quaternary amino groups of the $\mathrm{Q}_{6} \mathrm{DMAEMA}$ units, respectively. The degree of quaternization was determined to be $48 \%$. The same methodology was followed in order to determine the quaternization degree of the $\mathrm{P}$ (DMAEMA-co- $\mathrm{Q}_{12}$ DMAEMA)- $b$-POEGMA random diblock copolymer (quaternization agent: 1-iodododecane), derived from the partial quaternization of PDMAEMA $42-b$-POEGMA 12 that is depicted in Figure $2 \mathrm{~b}$. The degree of polymerization was determined to $20 \%$, which completely agrees with the theoretical one using 1-iodohexane. Generally, the degrees of quaternization found by NMR were in almost complete accordance with the theoretical values calculated by using the molar ratio of the alkyl halide to the DMAEMA monomeric units [44]. Moreover, in each case of the P(DMAEMA-co-Q ${ }_{6}$ DMAEMA)- $b$-POEGMA (Figure 2a) the weight composition of the POEGMA block was determined by integrating the peak of the methylene proton groups at $3.74 \mathrm{ppm}$. The same methodology was followed for each one of the remaining modified random diblock copolymers. The different quaternization degrees when using the same halide, along with the weight composition of PDMAEMA homopolymers, PDMAEMA- $b$ POEGMA precursor diblocks and the resulted eight partially modified random copolymers are presented in Table 1. Further confirmation of the modified chemical structure of the diblock copolymer precursor was accomplished by utilizing ATR-FTIR measurements. A representative example of comparative spectra of diblock precursor and its analogue can be found in SI (Figure S3). 

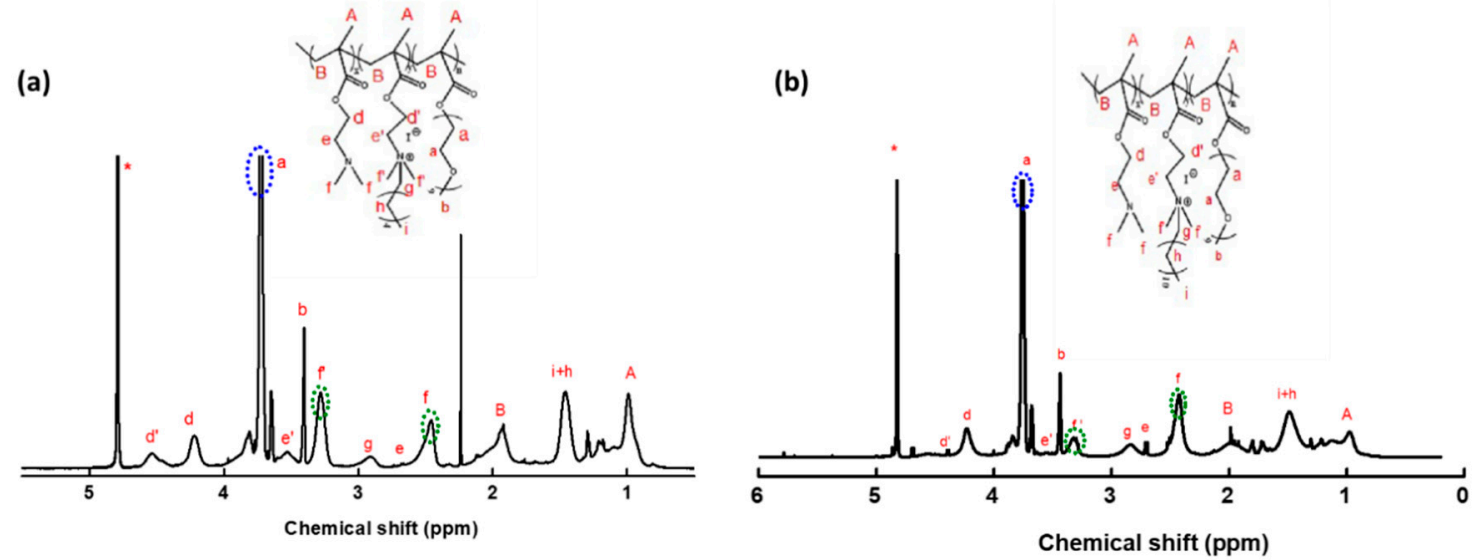

Figure 2. ${ }^{1} \mathrm{H}-\mathrm{NMR}$ spectra for (a) P(DMAEMA-co-Q 6 DMAEMA)- $b$-POEGMA and (b) P(DMAEMA-co-Q ${ }_{12}$ DMAEMA)- $b$ POEGMA in $\mathrm{D}_{2} \mathrm{O}$.

\subsection{Self-Assembly of the P(DMAEMA-co- $Q_{6 / 12}$ DMAEMA)-b-POEGMA Random Diblock Copolymers in Aqueous Media}

Studies on the ability of the resulted eight novel P(DMAEMA-co- $Q_{6 / 12}$ DMAEMA)$b$-POEGMA diblocks to self-assemble in aqueous media were conducted. In contrast to the double hydrophilic PDMAEMA-b-POEGMA precursor diblocks, their partially quaternized analogues are expected to exhibit amphiphilic character due to the incorporation of long hydrophobic chains. Partial quaternization reaction results in cationic units and the formation of the P(DMAEMA-co-QDMAEMA) random block. Subsequently, the amphiphilic character of the random diblock copolymers should define the formation of nanoaggregates. Based on the nature and sequence of the blocks, the P(DMAEMA-coQDMAEMA) random block should occupy the core-like region and the POEGMA block the corona of the aggregates. When inserted in aqueous media, it is expected that the presence of the hydrophobic groups would result in intramolecular interactions of the pendant groups leading to hydrophobic nanodomains [46] and thus the formation of nanoaggregates, whose morphological features will depend on the hydrophobic chain length and the quaternization degree. Due to close spatial vicinity of hydrophilic and hydrophobic groups the inner regions of the aggregates are expected to include hydrophobic microdomains but also water due to both the hydrophilic character of the DMAEMA units at $\mathrm{pH}=7$ and $\mathrm{T}=25^{\circ} \mathrm{C}$ and that of the cations attached to the quaternary amines of the modified QDMAEMA residues. Subsequently, the interface between corona and core may not be so well-defined as in normal core-shell micelles formed by traditional diblock copolymers. The morphology, mass and size of the nanoassemblies is expected to be affected by the length of the alkyl chain and the quaternization degree. The nanostructures formed from the self-assembly of the random diblock copolymers that contain alkyl chains of twelve carbon atoms are anticipitated to present more hydrophobic character. This hypothesis is based on the existence of longer hydrophobic chains and thus amplification of hydrophobic interactions that will result to lower interaction with water molecules [61]. Furthermore, the coexistence of DMAEMA units along with QDMAEMA residues will affect the response of DMAEMA units to $\mathrm{pH}$ and temperature changes. As a result, further aggregation or disaggregation may occur due to protonation or deprotonation of the amine groups of the DMAEMA segments, induced by altering the solution $\mathrm{pH}$. In case of temperature increase, the phase transition from a hydrated/hydrophilic state to dehydrated/more hydrophobic state is expected to occur at lower temperature values than the reported LCST of the PDMAEMA homopolymer. This particular behavior is assigned to the presence of entirely hydrophobic molecules that will assist to the dehydration of the polymeric system due to amplification of the hydrophobic interactions [61]. Light scattering techniques were utilized to examine the self-assembly of the modified diblock copolymers 
in aqueous solutions as a response to $\mathrm{pH}$ and temperature changes. DLS was utilized to acquire the hydrodynamic radius $\left(\mathrm{R}_{\mathrm{h}}\right.$, size indicator) and the size polydispersity index (PDI) of the formed nanoassemblies. PDI is extracted by using the cumulant method, while $R_{h}$ is obtained by the CONTIN algorithm. SLS was applied to obtain the average scattering intensity values (I) (a parameter that primarily indicates alterations in mass of the aggregates) and the $\mathrm{R}_{\mathrm{g}} / \mathrm{R}_{\mathrm{h} 0}$ ratios (in combination with DLS) and for detecting the $\mathrm{pH}$ response of the polymer chains. ELS was also conducted in order to define the $\zeta$-potential values and overall surface charge of the nanoassemblies at varying $\mathrm{pHs}$, i.e., at neutral, acidic and basic $\mathrm{pH}$ and at two temperatures i.e., $25^{\circ} \mathrm{C}$ and $45^{\circ} \mathrm{C}$.

\subsection{1. $\mathrm{pH}$ Effects on the Self-Assembly Behavior of the}

\section{P(DMAEMA-co-Q ${ }_{6} /{ }_{12}$ DMAEMA)-b-POEGMA Random Diblock Copolymers}

Taking into account, the sequence of the diblock copolymers, the nature of the monomers and their functionality, the distribution of distinct monomeric units in a random fashion within one block, the study of $\mathrm{pH}$ and temperature effects on the aqueous solutions of the random diblock copolymers seemed mandatory. In order to examine, the $\mathrm{pH}$-response of the aqueous solutions, the investigations were held at three different $\mathrm{pH}$ values, namely at $\mathrm{pH}=7$ (neutral), 3 (acidic) and 10 (basic), representative of the entire $\mathrm{pH}$ range. For the preparation of the aqueous solutions at $\mathrm{pH}=7$ and $\mathrm{T}=25^{\circ} \mathrm{C}$, two protocols were used. The first one includes the addition of distilled water at a vial containing the dry solid and then heating the mixture to $60^{\circ} \mathrm{C}$, until dissolution occurs. The measurements were held at $\mathrm{T}=25^{\circ} \mathrm{C}$, after equilibrium was achieved (see Section 2.4). The second one includes the dissolution of the dry solid at THF, its subsequent mixture with distilled water and afterwards the evaporation of the organic solvent. The solution was examined at $\mathrm{T}=25^{\circ} \mathrm{C}$, after equilibrium was accomplished (see Section 2.2). The choice to include two preparation protocols was based on the possible effects of each protocol on the morphology of the nanoaggregates and their colloidal stability over time, since nanoparticles formed using organic solvents are smaller in size and more thermodynamically stable [12,62]. The self-assembly characteristics upon $\mathrm{pH}$-variations were compared according to the preparation protocol, matching nominal quaternination degree and nature of alkyl chains for the derivatives resulted from the partial quaternization of the PDMAEMA block of the same precursor block copolymer. The concentrations of the aqueous solutions of the analogues derived from the partial quaternization of the PDMAEMA ${ }_{56}-b-\mathrm{POEGMA}_{86}$, $\mathrm{i}$, prepared by the direct dissolution in the aqueous medium were $1 \times 10^{-3} \mathrm{~g} / \mathrm{mL}$ and $5 \times 10^{-3} \mathrm{~g} / \mathrm{mL}$. Below, discussion over the $\mathrm{pH}$-response of the $\mathrm{Q}_{6}$ and $\mathrm{Q}_{12}$ derivatives of the first precursor of the same theoretical quaternization degree, when the preparation protocol of direct dissolution in aqueous media was used, is conducted.

pH-Response of P(DMAEMA ${ }_{45}-$ DO-Q $_{6}$ DMAEMA $\left._{11}\right)-b$-POEGMA 86 and P(DMAEMA ${ }_{44}-$ Co- $_{12}$ DMAEMA $\left._{12}\right)-b-$ POEGMA $_{86}$ for the Case of Direct Dissolution in the Aqueous Medium

According to Figure $3 a$ the scattering intensity of the $\mathrm{Q}_{6}$ diblock is considerably higher than the one of $\mathrm{Q}_{12}$ diblock at $\mathrm{pH}=7$, indicating the formation of nanoparticles of smaller mass when 1-iodododecane was used as the quaternization agent. This phenomenon is correlated to the existence of fewer but longer hydrophobic chains, resulting to initial aggregation due to a greater amplification of hydrophobic interactions and the formation of nanoaggregates of smaller mass. This behavior is also fully supported by the aggregation numbers $\left(\mathrm{N}_{\mathrm{agg}}\right)$ obtained for both samples by the SLS technique $\mathrm{N}_{\mathrm{agg}}$ of the $\mathrm{Q}_{6}$ sample with quaternization degree of $19 \%$, at $\mathrm{pH} 7$ was determined to be $55( \pm 2.75)$ and $37( \pm 1.85)$ for the $\mathrm{Q}_{12}$ samples with degree of quaternization $20 \%$ ). Moreover, based on the observation of the hydrodynamic radius versus $\mathrm{pH}$ variations, the nanoaggregates formed from the self-assembly of $\mathrm{Q}_{12}$ sample $\left(\mathrm{R}_{\mathrm{h}}=133 \pm 6.65 \mathrm{~nm}\right)$, at $\mathrm{pH}=7$, are of higher dimensions than the ones of $Q_{6}$ samples $\left(R_{h}=99 \pm 4.95 \mathrm{~nm}\right)$. This may be also a result of better packing of the $Q_{6}$ aggregates due to the shorter alkyl chains. Moreover, another population of smaller size is observed in the case of sample $Q_{12}$, that is assigned to the presence of unimers 
$\left(R_{h}=5 \pm 0.25 \mathrm{~nm}\right)$. Both observations are also supported by the lower scattering intensity values, the participation of fewer polymeric chains in the nanoassemblies formation and the smaller aggregation number. The coexistence of unimers and aggregates in the case of sample $Q_{12}$ and the presence of only one population in the case of $Q_{6}$ sample, at $\mathrm{pH}=7$, are shown in the size distribution from CONTIN analysis, displayed in Figure 4.
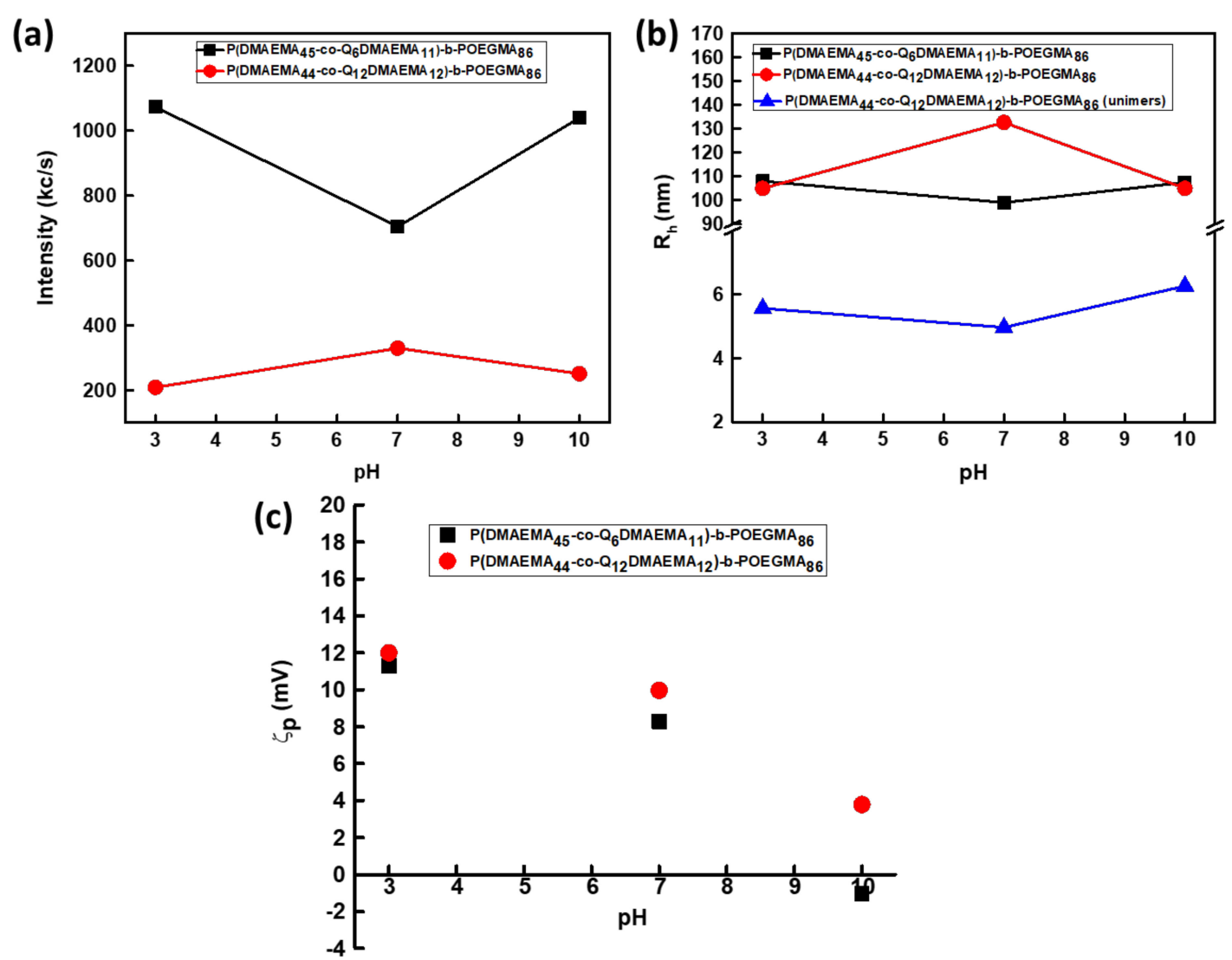

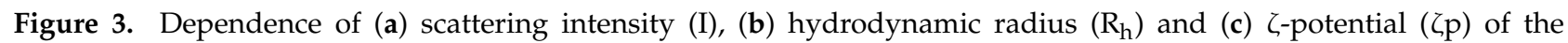

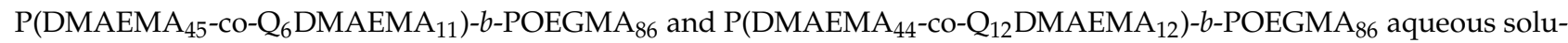
tions upon $\mathrm{pH}$-variations, when the preparation protocol utilized was the direct dissolution in aqueous medium $\left(\mathrm{c}=5 \times 10^{-3} \mathrm{~g} / \mathrm{mL}\right)$.

(a)

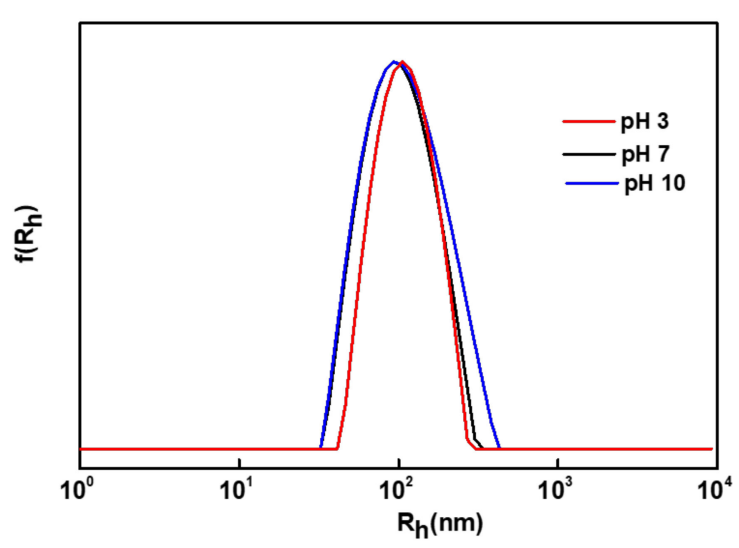

(b)

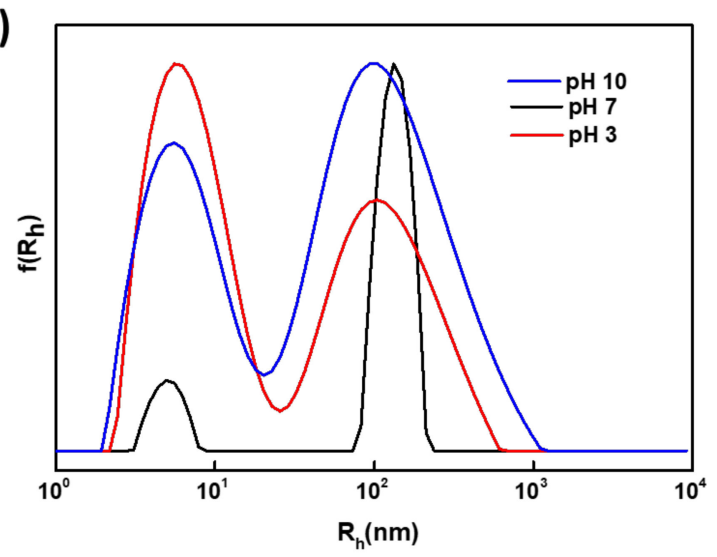

Figure 4. Size distributions from CONTIN analysis, at $\mathrm{pH} \mathrm{7,3}$ and 10, obtained by measurements held at $90^{\circ}$, for the

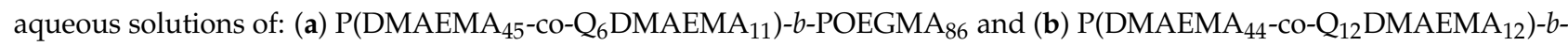
POEGMA $_{86}$. 
As far as, the $\mathrm{pH}$ response is concerned, both $\mathrm{Q}_{6}$ and $\mathrm{Q}_{12}$ diblocks are responding to variations of $\mathrm{pH}$ but quite differently. In the case of $\mathrm{Q}_{6}$, at $\mathrm{pH}=3$, further aggregation occurs taking into consideration the increase in the scattering intensity compared with that at $\mathrm{pH}=7$, along with the increase of the hydrodynamic radius which at $\mathrm{pH}=3$ was determined at $108 \pm 5.4 \mathrm{~nm}$. This behavior is not the anticipated one, as shifting from neutral $\mathrm{pH}$ to acidic would provoke protonation of the amine groups of the DMAEMA units and subsequent disaggregation of the nanostructures. However, the complex morphology of the aggregates maybe accountable for the observed behavior. Increased aggregation may result by the presence of long alkyl chains which surround the amino groups, making them less accessible to hydrogen ions. Aggregation number also supports this conclusion $\left(\mathrm{N}_{\mathrm{agg}}=83 \pm 4.2\right)$. When the $\mathrm{pH}$ turns 10 from 7 , the scattering intensity and the hydrodynamic radius increase (to $R_{h}=104 \pm 5.2 \mathrm{~nm}$ ) due to further aggregation. The deprotonation of the amino groups at $\mathrm{pH} 10$, provokes further aggregation phenomena. The latter are enhanced by the hydrophobic interactions from the presence of alkyl chains. The aggregation number also is increased at $\mathrm{pH}=10$. In the case of $\mathrm{Q}_{12}$ diblock, a $\mathrm{pH}$-dependent behavior is observed. At $\mathrm{pH}=3$, based on the decrease in both scattering intensity and $\mathrm{R}_{\mathrm{h}}$ values $\left(R_{h}=150 \pm 7.5 \mathrm{~nm}\right)$, the protonation of the amino group of the DMAEMA segments results in some splitting of the nanoaggregates. Aggregation number $\left(\mathrm{N}_{\mathrm{agg}}=23\right)$ is in accordance with the above analysis. Unimers $\left(\mathrm{R}_{\mathrm{h}}=5 \pm 0.25 \mathrm{~nm}\right)$ also exist at $\mathrm{pH}=3$ and, based on the size distribution from CONTIN analysis (Figure $4 \mathrm{~b}$ ), the number of unimers is increased compared with that at $\mathrm{pH}=3$. At $\mathrm{pH}=10$, the scattering intensity is decreased from that at $\mathrm{pH}=7$ accompanied with a decrease in $\mathrm{R}_{\mathrm{h}}$ value $\left(\mathrm{R}_{\mathrm{h}}=107 \pm 7.5 \mathrm{~nm}\right)$, foreshadowing disaggregation phenomena. The aggregation number determined $\left(\mathrm{N}_{\mathrm{agg}}=30 \pm 1.5\right)$ is in agreement with the above observation. From CONTIN analysis the existence of both unimers $\left(R_{h}=6 \pm 0.3 \mathrm{~nm}\right)$ and aggregates is shown. The latter behavior was not expected, as deprotonation of the amino groups would generate further aggregation. Trying to explain this kind of response, one can reach to the conclusion that the nanoassemblies at $\mathrm{pH} 10$ are not thermodynamically stable, taking also into consideration the high PDI value and the wide size distribution observed. The above hypothesis also applies to the nanoassemblies formed at $\mathrm{pH}=3$. The high PDI values for the $\mathrm{Q}_{12}$ sample, at all three $\mathrm{pHs}$ can be explained by the coexistence of two distinct populations (Figure $4 \mathrm{~b}$ ) and the random nature of the $\left(\mathrm{PDMAEMA}_{44}-\mathrm{Co}-\mathrm{Q}_{12} \mathrm{DMAEMA}_{11}\right.$ ) block. The physicochemical characteristics of the diblocks at the aforementioned solution conditions are summarized in Table 2.

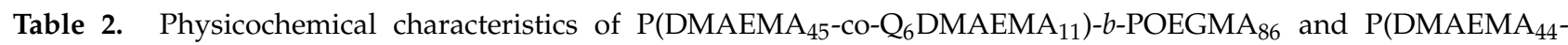

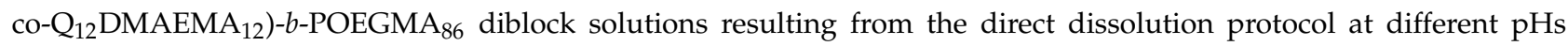
$\left(\mathrm{c}=5 \times 10^{-3} \mathrm{~g} / \mathrm{mL}\right)$.

\begin{tabular}{|c|c|c|c|c|c|c|c|}
\hline \multicolumn{8}{|c|}{ Direct Dissolution Preparation Protocol } \\
\hline Sample & $\begin{array}{c}\text { Quaternization } \\
\text { Degree }(\%)^{a}\end{array}$ & $\mathrm{pH}$ & $R_{h} b, e(n m)$ & PDI $^{b}$ & $N_{a g g}{ }^{c, e}$ & $\mathbf{R}_{\mathrm{g}} / \mathbf{R}_{\mathrm{h} 0} \mathrm{b,c}$ & $\zeta_{\mathrm{p}} \mathrm{d}, \mathrm{e}(\mathrm{mV})$ \\
\hline \multirow{3}{*}{$\begin{array}{l}\text { P(DMAEMA } \\
\text { DM }_{5}-\mathrm{Co}- \\
\left.\mathrm{Q}_{6} \text { DMAEMA }_{11}\right)-b- \\
\text { POEGMA }_{86} \\
\left(1 \mathrm{Q}_{6}\right)\end{array}$} & \multirow{3}{*}{19} & 3 & 108 & 0.35 & 83 & 0.75 & 11 \\
\hline & & 7 & 99 & 0.32 & 55 & 0.65 & 8.3 \\
\hline & & 10 & 105 & 0.29 & 90 & 0.8 & -1 \\
\hline \multirow{3}{*}{$\begin{array}{c}\text { P(DMAEMA }{ }_{44}-\mathrm{Co}- \\
\left.\mathrm{Q}_{12} \text { DMAEMA }_{12}\right)-b- \\
\text { POEGMA }_{86} \\
\left(1 \mathrm{Q}_{12}\right)\end{array}$} & \multirow{3}{*}{20} & 3 & $5 / 150$ & 0.44 & 37 & - & 12 \\
\hline & & 7 & $5 / 133$ & 0.41 & 30 & - & 9.98 \\
\hline & & 10 & $6 / 107$ & 0.45 & 23 & - & 3 \\
\hline
\end{tabular}

${ }^{\text {a }}$ Determined by ${ }^{1} \mathrm{H}-\mathrm{NMR},{ }^{\mathrm{b}}$ Determined by DLS at measuring angle $90^{\circ},{ }^{\mathrm{c}}$ Determined by SLS, ${ }^{\mathrm{d}}$ Determined by ELS, ${ }^{\mathrm{e}}$ Values of $\mathrm{R}_{\mathrm{h}}, \mathrm{N}_{\mathrm{agg}}$ and $\zeta_{p}$ were determined with a standard deviation of $\pm 5 \%$. Note: The two different $R h$ values correspond to two different populations detected in the solution. The smaller one (fist value) is assigned to unimers, while the bigger one (second value) is assigned to aggregates.

Combination of DLS and SLS techniques was used in order to determine the $\mathrm{R}_{\mathrm{g}} / \mathrm{R}_{\mathrm{h} 0}$ ratios at all three $\mathrm{pH}$ values as this parameter provides more information about the morphology of the nanostructures $[63,64]$. As far as the $1 Q_{6}$ diblock is concerned, the $R_{g} / R_{h 0}$ 
values are in the range 0.65 to 0.80 . According to existing literature $R_{g} / R_{h 0}$ values in this range indicate the presence of nanostructures of spherical geometry with a relatively compact structure $[63,64]$. The surface charge of both samples as a function of $\mathrm{pH}$ changes (Figure 3c), was monitored by ELS technique. At $\mathrm{pH}=71 \mathrm{Q}_{6}$ diblock presents $\zeta$-potential of $+8.29( \pm 0.4) \mathrm{mV}$, while $1 \mathrm{Q}_{12}$ of $+9.98( \pm 0.5) \mathrm{mV}$. Both values are in accordance with the permanent cationic charges induced by partial quaternization, combined with the nature of the random diblock copolymers that promotes the not well-defined interface between corona and inner hydrophobic region and the partial protonation of the DMAEMA segments. At $\mathrm{pH}=3$, the $\zeta$-potential values are $+11( \pm 0.55) \mathrm{mV}$ and $+12( \pm 0.6) \mathrm{mV}$ accordingly. At $\mathrm{pH}=10$ the $\zeta$-potential of the $1 \mathrm{Q}_{6}$ diblock is $-1( \pm 0.05) \mathrm{mV}$ due to the deprotonation of the amino groups of the DMAEMA segments. However, the $\zeta$-potential value of the $1 \mathrm{Q}_{12}$ is slightly positive $(+3 \pm 0.15 \mathrm{mV})$ at $\mathrm{pH}=10$ but within the anticipated range.

pH-Response of P(DMAEMA ${ }_{30}$-co-Q ${ }_{6}$ DMAEMA $\left._{26}\right)-b$-POEGMA 86 and $\mathrm{P}\left(\mathrm{DMAEMA}_{28}-\mathrm{Co}-\mathrm{Q}_{12} \mathrm{DMAEMA}_{28}\right)-\bar{b}-\mathrm{POEGMA}_{86}$ Solutions from the Direct Dissolution in the Aqueous Medium

Accordingly, diblocks $2 \mathrm{Q}_{6}$ and $2 \mathrm{Q}_{12}$ were compared based on the response they present to $\mathrm{pH}$ variations. Based on the scattering intensity recorded as a function of $\mathrm{pH}$ (Figure 5), the self-assembly behavior at $\mathrm{pH}=7$ (before changing the solution $\mathrm{pH}$ ), resulted in the formation of nanoaggregates of higher mass in the case of $2 \mathrm{Q}_{12}$ compared to the $2 \mathrm{Q}_{6}$ case. This latter behavior is assigned mostly in the increase in the quaternization degree of the diblocks and the formation of aggregates. This conclusion is fully supported by the recorded aggregation number (at pH $7 \mathrm{~N}_{\text {agg }}$ for $2 \mathrm{Q}_{6}$ is $65( \pm 3.3)$ and for $2 \mathrm{Q}_{12}$ is $110( \pm 5.5)$ ). The reversed tendency is observed as far as the size of the nanoparticles is concerned. Specifically, the $R_{h}$ value of $2 Q_{12}$ at $\mathrm{pH} 7$ is $69 \mathrm{~nm}( \pm 3.5 \mathrm{~nm})$ and for $2 \mathrm{Q}_{6}$ is $206 \mathrm{~nm}( \pm 10 \mathrm{~nm})$. Due to the higher hydrophobic character of $2 \mathrm{Q}_{12}$, more compact aggregates are formed. Moreover, for the $2 \mathrm{Q}_{12}$ diblock the absence of unimers is observed, in contrast to the $1 \mathrm{Q}_{12}$ diblock as the amplified hydrophobic character induces the participation of all polymeric chains in the formation of nanoaggregates.

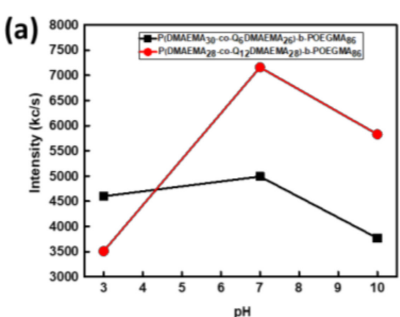

(d)

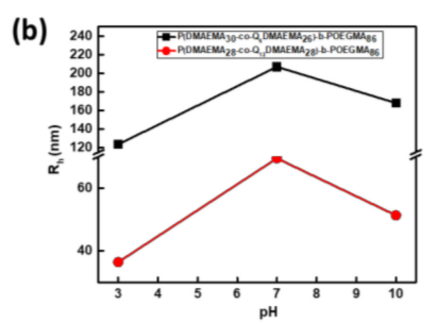

(c)

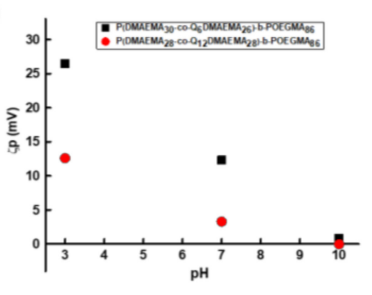

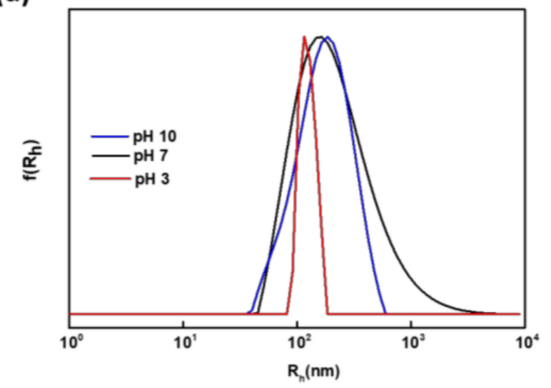

(e)

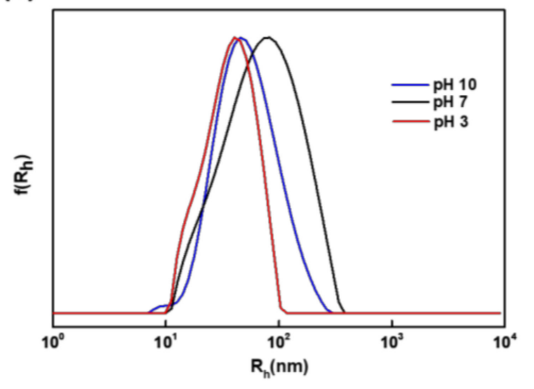

Figure 5. Dependence of (a) scattering intensity (I), (b) hydrodynamic radius $\left(R_{h}\right)$ and (c) surface charge $\left(\zeta_{\mathrm{p}}\right)$ for the

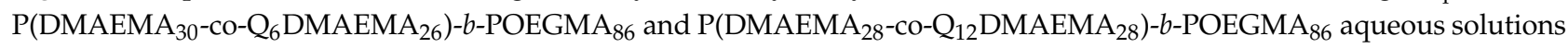
on $\mathrm{pH}$-variations and size distribution from CONTIN analysis obtained at $90^{\circ}$, at $\mathrm{pH} 7,3$ and 10 for (d) $\mathrm{P}\left(\mathrm{DMAEMA}_{30}\right.$-co- $^{-}$

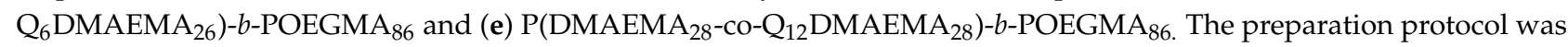
the direct dissolution in aqueous medium and the concentration of the solution $5 \times 10^{-3} \mathrm{~g} / \mathrm{mL}$. 
For the $2 \mathrm{Q}_{12}$ diblock when the solution $\mathrm{pH}$ changes from 7 to 3 , the deprotonation of the amino groups of the DMAEMA residues results in disaggregation which is designated by the abrupt decrease in scattering intensity, size $\left(R_{h}=36 \pm 1.8 \mathrm{~nm}\right)$ and aggregation number $\left(\mathrm{N}_{\mathrm{agg}}=45 \pm 2.25\right)$. A non-expected behavior is observed when the solution $\mathrm{pH}$ changes to 10, where disaggregation occurs, even though further aggregation due to the deprotonation of the tertiary amines of DMAEMA was a more possible scenario. This observation is supported by the values of all the physicochemical parameters studied (at $\mathrm{pH}=10, \mathrm{R}_{\mathrm{h}}=51 \pm 2.6 \mathrm{~nm}$ and $\mathrm{N}_{\mathrm{agg}}=75 \pm 3.8$ ). This behavior may be assigned to the peculiar morphology of the formed nanoaggregates or to the fact that they are not in thermodynamic equilibrium. For the $2 \mathrm{Q}_{6}$ diblock, a similar behavior, has been monitored but not of the same magnitude. These physicochemical quantities are displayed in Table 3. The similar behavior at $\mathrm{pH} 10$ for both samples points to the conclusion that the increase of $\mathrm{pH}$ and thus amplification of the hydrophobic character of the chains induces the formation of thermodynamically unstable nanostructures. Size distributions from CONTIN analysis confirm the existence of one kind of population for both diblocks at all $\mathrm{pHs}$. For $2 \mathrm{Q}_{6}$ diblock the size distribution peaks are rather broad and not so symmetrical, except for the $\mathrm{pH}=3$ case which is relatively narrow and symmetrical, with a lower PDI value (see Table 3). For the $2 \mathrm{Q}_{12}$ diblock the absence of unimers is confirmed.

Table 3. Physicochemical features of the P(DMAEMA $\left.{ }_{30}-\mathrm{DO}_{-} \mathrm{Q}_{6} \mathrm{DMAEMA}_{26}\right)-b-\mathrm{POEGMA}_{86}$ and $\mathrm{P}\left(\mathrm{DMAEMA}_{28}-\mathrm{co}-\right.$ $\mathrm{Q}_{12}$ DMAEMA $_{28}$ )- $b$-POEGMA ${ }_{86}$, at direct dissolution protocol and solution concentration $\mathrm{c}=5 \times 10^{-3} \mathrm{~g} / \mathrm{mL}$, extracted from $\mathrm{pH}$-response studies.

\begin{tabular}{|c|c|c|c|c|c|c|c|}
\hline \multirow[b]{2}{*}{ Sample } & \multicolumn{6}{|c|}{ Direct Dissolution Preparation Protocol } & \multirow[b]{2}{*}{$\zeta_{\mathrm{p}} \mathrm{d}, \mathrm{e}(\mathrm{mV})$} \\
\hline & $\begin{array}{c}\text { Quaternization } \\
\text { Degree (\%) }\end{array}$ & $\mathrm{pH}$ & $\underset{(\mathrm{nm})}{\mathbf{R}_{\mathrm{h}} \mathrm{b}, \mathrm{e}}$ & PDI $^{b}$ & $\mathbf{N}_{\text {agg }}{ }^{c, e}$ & $R_{g} / R_{h 0} b, c$ & \\
\hline \multirow{3}{*}{$\begin{array}{c}\mathrm{P}\left(\mathrm{DMAEMA}_{30}-\mathrm{co}-\right. \\
\left.\mathrm{Q}_{6} \mathrm{DMAEMA}_{26}\right)^{-b-} \\
\text { POEGMA }_{86} \\
\left(2 \mathrm{Q}_{6}\right)\end{array}$} & \multirow{3}{*}{46} & 3 & 124 & 0.29 & 60 & 0.6 & 26 \\
\hline & & 7 & 206 & 0.4 & 65 & 0.7 & 12 \\
\hline & & 10 & 167 & 0.37 & 45 & 0.67 & 0.9 \\
\hline \multirow{3}{*}{$\begin{array}{l}\mathrm{P}\left(\mathrm{DMAEMA}_{28}-\mathrm{co}-\right. \\
\left.\mathrm{Q}_{12} \mathrm{DMAEMA}_{28}\right)-b- \\
\text { POEGMA }_{86} \\
\left(2 \mathrm{Q}_{12}\right)\end{array}$} & \multirow{3}{*}{50} & 3 & 36 & 0.4 & 45 & 0.7 & 13 \\
\hline & & 7 & 69 & 0.45 & 110 & 0.8 & 3.2 \\
\hline & & 10 & 72 & 0.35 & 72 & 0.72 & -0.27 \\
\hline
\end{tabular}

${ }^{\text {a }}$ Determined by ${ }^{1} \mathrm{H}-\mathrm{NMR},{ }^{\mathrm{b}}$ Determined by DLS at a measuring angle $90^{\circ},{ }^{\mathrm{c}}$ Determined by SLS, ${ }^{\mathrm{d}}$ Determined by ELS, ${ }^{\mathrm{e}}$ Values of $\mathrm{R}_{\mathrm{h}}$, $\mathrm{N}_{\mathrm{agg}}$ and $\zeta_{\mathrm{p}}$ were determined with a standard deviation of $\pm 5 \%$.

$\mathrm{R}_{\mathrm{g}} / \mathrm{R}_{\mathrm{h} 0}$ values obtained after extrapolation at zero angle, at all cases, indicate the formation of nanoaggregates of spherical shape with rather compact inner structure. $2 \mathrm{Q}_{6}$ diblock exhibits higher surface charge than $2 \mathrm{Q}_{12}$. The latter fact may be attributed to the configuration of the polymeric chains that comprise the nano-structures. Apparently, the cationic components are located in the particle surface. The higher $\zeta_{\mathrm{p}}$ values at $\mathrm{pH} 3$ and the lower values at $\mathrm{pH} 10$ (in comparison with the ones at $\mathrm{pH} 7$ ) are expected to the protonation/deprotonation equilibria of DMAEMA segments, respectively.

It is worth mentioning that when the concentration of the aqueous solution was $1 \times 10^{-3} \mathrm{~g} / \mathrm{mL}$ for all four copolymers derived from the PDMAEMA P6 $_{5} b-$ POEGMA $_{86}$ precursor, the scattering intensity was below $30 \mathrm{kc} / \mathrm{s}( \pm 1.5)$ indicating that polymeric chains are actually molecularly dissolved in the aqueous medium. Therefore higher concentrations are eeded for the formation of aggregates in these polymeric systems.

pH-Response of P(DMAEMA ${ }_{30}-$ Co- $_{6}$ DMAEMA $\left._{26}\right)-b$-POEGMA 86 and

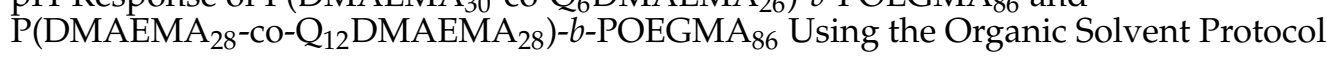

In this section, the results from the aqueous solutions of $2 \mathrm{Q}_{6}$ and $2 \mathrm{Q}_{12}$ samples as a function of $\mathrm{pH}$ changes, prepared by using the organic solvent (THF) solution preparation protocol, are discussed. The choice over studying the samples of about $50 \%$ quaterniza- 
tion degree was based on the fact that the increased hydrophobic character should induce the formation of well-defined nanoparticles with ameliorated features and enhanced $\mathrm{pH}$-response. The use of this protocol offers the prospect of formation of nanoparticles closer to equilibrium [12]. The concentration of the investigated aqueous solutions was $1 \times 10^{-3} \mathrm{~g} / \mathrm{mL}$.

Response to $\mathrm{pH}$ changes is observed in both cases, however, the two diblocks exhibit different behavior, due to the fact that there are a longer alkyl chains present in the $2 \mathrm{Q}_{12}$ diblock. The self-assembly of the $2 \mathrm{Q}_{12}$ diblock at $\mathrm{pH}=7$, leads to the formation of aggregates of lower mass (scattering intensity is lower) and higher size $\left(R_{h}=44 \pm 2.2 \mathrm{~nm}\right)$ than $2 \mathrm{Q}_{6}\left(\mathrm{R}_{\mathrm{h}}=66 \pm 3.3 \mathrm{~nm}\right)$, indicating that fewer polymeric chains aggregate towards formation of nanoparticles. This is supported by the lower scattering intensity that sample $2 \mathrm{Q}_{12}$ exhibits at $\mathrm{pH}=7$, compared to $2 \mathrm{Q}_{6}$ sample and the obtained aggregation numbers $\left(\mathrm{N}_{\mathrm{agg}}\right.$ of $2 \mathrm{Q}_{12}=79( \pm 4)$ and of $\left.2 \mathrm{Q}_{6}=85( \pm 4.3)\right)$. The incorporation of longer alkyl chains increases the hydrophobic character of the diblock chains and thus fewer molecules are required for the formation of stable nanoparticles. The $\mathrm{pH}$-response of diblock $2 \mathrm{Q}_{6}$ is in agreement with the anticipated one. The protonation of the amino groups of the amino groups of DMAEMA that occurs at $\mathrm{pH}=3$ results in partial disaggregation of the originally formed nanostructures. The latter conclusion is based on the decrease in the scattering intensity (at pH $=3: \mathrm{I}=1550 \mathrm{kc} / \mathrm{s}( \pm 78)$, at $\mathrm{pH}=7: \mathrm{I}=2245 \mathrm{kc} / \mathrm{s}( \pm 112))$, that is accompanied with a decrease in the aggregation number $\left(\mathrm{N}_{\mathrm{agg}}=75\right)$. Even though, no significant change was monitored concerning the hydrodynamic radius $\left(\mathrm{R}_{\mathrm{h}}=76 \mathrm{~nm}( \pm 3.8)\right.$ at $\left.\mathrm{pH} 3\right)$ indicating that the disaggregation results in "swelling" of the nanostructures. A slight increase in the scattering intensity occurs at $\mathrm{pH}=10(\mathrm{I}=2450 \pm 123 \mathrm{kc} / \mathrm{s})$, indicating further aggregation that is also supported by the increase of the aggregation number $\left(\mathrm{N}_{\mathrm{agg}}=102 \pm 5.1\right)$. Similarly with the $\mathrm{pH}=3$ case, no major difference was monitored in the hydrodynamic radius, denoting that further aggregation results in more compact nanoparticles probably with less water molecules inside. Moreover, the $\mathrm{pH}$ response of the $2 \mathrm{Q}_{6}$ diblock is also confirmed from the size distribution. All three peaks are relatively narrow and symmetrical. The monomodal peaks proved once more the existence of one population at each case. From the position of each peak, it can be concluded that at $\mathrm{pH}=10$, nanostructures of slightly higher mass are present than the ones at $\mathrm{pH} 7$ and 3, due to further aggregation that the deprotonation of the amino groups of the DMAEMA units induces. Moreover, the smaller nanoassemblies are observed at $\mathrm{pH}=3$ due to the disaggregation of original nanoparticles as a result of protonation of the non-modified amino groups. On the contrary, the response of the $2 \mathrm{Q}_{12}$ diblock at $\mathrm{pH}$ variations is unexpected. When the solution $\mathrm{pH}$ decreases to 3 , further aggregation and formation of particles of larger mass occurs due to the presence of longer alkyl chains. The latter annotation is supported by the abrupt increase in scattering intensity ( $\mathrm{I}=3200 \pm 160 \mathrm{kc} / \mathrm{s}$ ), while the size of the nanoparticles almost doubles $\left(R_{h}=80 \pm 4 \mathrm{~nm}\right)$ and a second population of nanoparticles appears $\left(R_{h}=25 \pm 1.3 \mathrm{~nm}\right)$. The appearance of two distinct populations is also demonstrated at the size distribution from CONTIN at $\mathrm{pH} 3$ (Figure 6e). At $\mathrm{pH}=10$, the major increase in the scattering intensity $(\mathrm{I}=6800 \pm 340 \mathrm{kc} / \mathrm{s}$ at $\mathrm{pH}=10$, while $\mathrm{I}=1500 \pm 75 \mathrm{kc} / \mathrm{s}$ at $\mathrm{pH}=7)$, followed by the increase in size $\left(\mathrm{R}_{\mathrm{h}}=85 \pm 4.3 \mathrm{~nm}\right)$ and aggregation number $\left(\mathrm{N}_{\mathrm{agg}}=120 \pm 6\right)$ leads to the conclusion that further aggregation occurs at this $\mathrm{pH}$. The explanation of this behavior at $\mathrm{pH}=10$ has been stated in similar cases. All the physicochemical data are presented in Table 4. 


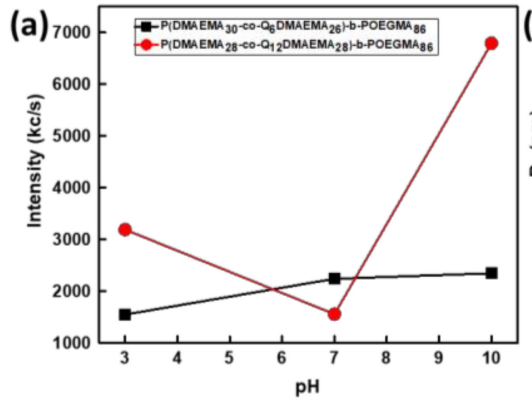

(d)

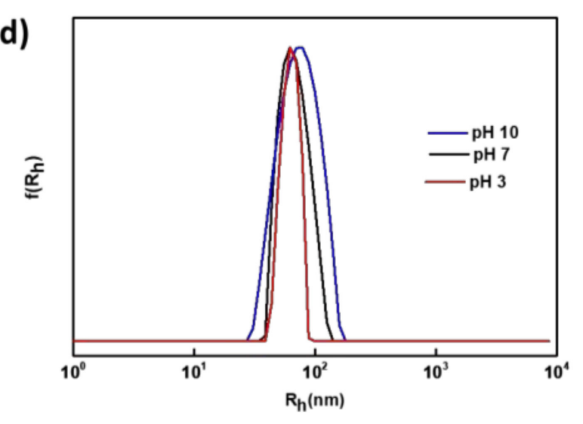

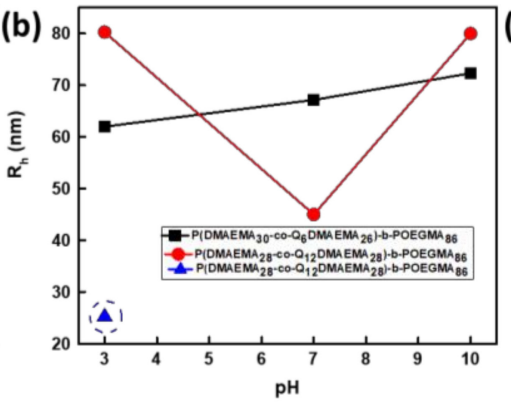

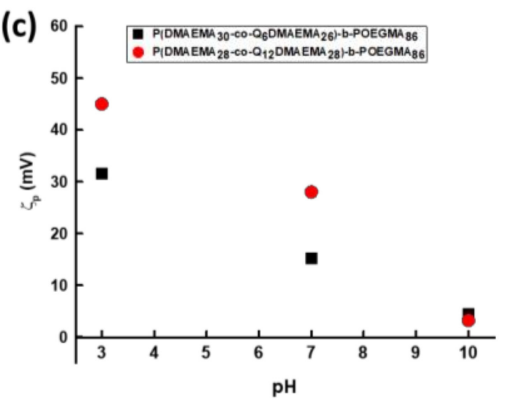

(e)

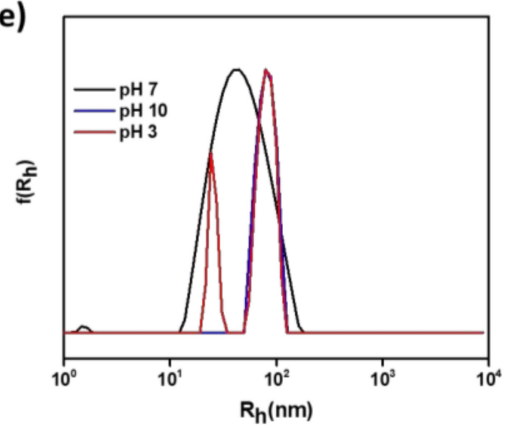

Figure 6. Dependence of (a) scattering intensity (I), (b) hydrodynamic radius $\left(R_{h}\right)$ and (c) surface charge $\left(\zeta_{\mathrm{p}}\right)$ for the

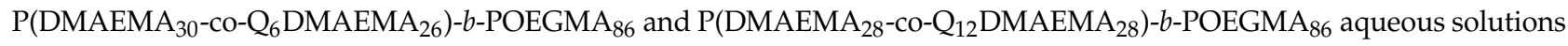
on $\mathrm{pH}$-variations and size distributions from CONTIN analysis obtained at $90^{\circ}$, at $\mathrm{pH} 7,3$ and 10 for $(\mathrm{d}) \mathrm{P}\left(\mathrm{DMAEMA}_{30}\right.$-co-

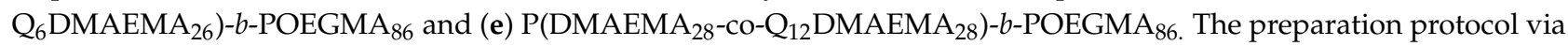
molecular dissolution in organic solvent was utilized and the concentration of the final polymer solution was $1 \times 10^{-3} \mathrm{~g} / \mathrm{mL}$.

Table 4. Physicochemical characteristics of the P(DMAEMA $\left.{ }_{30}-\mathrm{CO}_{-} \mathrm{Q}_{6} \mathrm{DMAEMA}_{26}\right)-b-\mathrm{POEGMA}_{86}$ and $\mathrm{P}\left(\mathrm{DMAEMA}_{28}-\right.$ $\mathrm{co} \mathrm{Q}_{12} \mathrm{DMAEMA}_{28}$ )- $b$-POEGMA 86 diblocks at different $\mathrm{pHs}$, from organic solvent protocol and solution concentration $\mathrm{c}=1 \times 10^{-3} \mathrm{~g} / \mathrm{mL}$.

\begin{tabular}{|c|c|c|c|c|c|c|c|}
\hline \multicolumn{8}{|c|}{ Organic Solvent (THF) Preparation Protocol } \\
\hline Sample & $\begin{array}{l}\text { Quaternization } \\
\text { Degree }(\%)^{a}\end{array}$ & pH & $\mathbf{R}_{\mathrm{h}} \mathbf{b , e}(\mathrm{nm})$ & PDI $^{b}$ & $\mathbf{N}_{\text {agg }}{ }^{c, e}$ & $\mathbf{R}_{\mathrm{g}} / \mathbf{R}_{\mathrm{h} 0} \mathrm{~b}, \mathrm{c}$ & $\zeta_{\mathrm{p}} \mathrm{d}, \mathrm{e}(\mathrm{mV})$ \\
\hline \multirow{3}{*}{$\begin{array}{c}\mathrm{P}\left(\mathrm{DMAEMA}_{30}-\mathrm{co}-\right. \\
\left.\mathrm{Q}_{6} \mathrm{DMAEMA}_{26}\right)-b- \\
\text { POEGMA }_{86} \\
\left(2 \mathrm{Q}_{6}\right)\end{array}$} & \multirow{3}{*}{46} & 3 & 62 & 0.32 & 75 & 0.6 & +32 \\
\hline & & 7 & 66 & 0.35 & 85 & 0.72 & +15 \\
\hline & & 10 & 72 & 0.3 & 102 & 0.63 & +3 \\
\hline \multirow{3}{*}{$\begin{array}{l}\mathrm{P}\left(\mathrm{DMAEMA}_{28}-\mathrm{co}-\right. \\
\left.\mathrm{Q}_{12} \text { DMAEMA }_{28}\right)^{-b-} \\
\text { POEGMA }_{86} \\
\left(2 \mathrm{Q}_{12}\right)\end{array}$} & \multirow{3}{*}{50} & 3 & $25 / 80$ & 0.33 & 83 & - & +46 \\
\hline & & 7 & 44 & 0.38 & 79 & 0.65 & +28 \\
\hline & & 10 & 85 & 0.35 & 150 & 0.8 & +3.5 \\
\hline
\end{tabular}

${ }^{\text {a }}$ Determined by ${ }^{1} \mathrm{H}-\mathrm{NMR},{ }^{\mathrm{b}}$ Determined by DLS at measuring angle $90^{\circ},{ }^{\mathrm{c}}$ Determined by SLS, ${ }^{\mathrm{d}}$ Determined by ELS, ${ }^{\mathrm{e}}$ Values of $\mathrm{R}_{\mathrm{h}}, \mathrm{N}_{\mathrm{agg}}$ and $\zeta_{p}$ were determined with a standard deviation of $\pm 5 \%$. Note: The two different $R_{h}$ values correspond to two different populations detected in the solution. The smaller one (fist value) is assigned to smaller aggregates, while the bigger one (second value) is assigned to bigger aggregates.

The $R_{\mathrm{g}} / \mathrm{R}_{\mathrm{h} 0}$ values obtained after extrapolation at zero angle fluctuate from 0.6 to 0.8 , indicating the formation of compact nanoaggregates of spherical shape. $2 \mathrm{Q}_{12}$ diblock aggregates exhibit higher surface charge than $2 \mathrm{Q}_{6}$, at all $\mathrm{pHs}$ examined. Apparently, more cationic charges are located on the particle surface. In both cases, the higher values are recorded at $\mathrm{pH} 3$ while the lower at $\mathrm{pH} 10$ (in comparison with ones at $\mathrm{pH} 7$ ) as expected. It should be also added that even though the lower $\zeta$-potential values are encountered at $\mathrm{pH}=10$ they are positive as a consequence of the increased number of cations present along the PDMAEMA block due to the higher quaternization degree. 
At this point, it is worth mentioning that judging from the polydispersity indexes of the solutions prepared by using THF, they are more homogenous than the solutions prepared from direct copolymer dissolution. Generally, the dimensions of the nanoassemblies from the organic solvent protocol are lower. The above-mentioned solutions were stable for more than 15 days (as confirmed by DLS), while the ones prepared by direct dissolution in aqueous media showed some evidence of precipitation after 3 days from the day of their preparation. A graphical illustration of the self-assembly behavior of the random block copolymers is shown in Scheme 2.

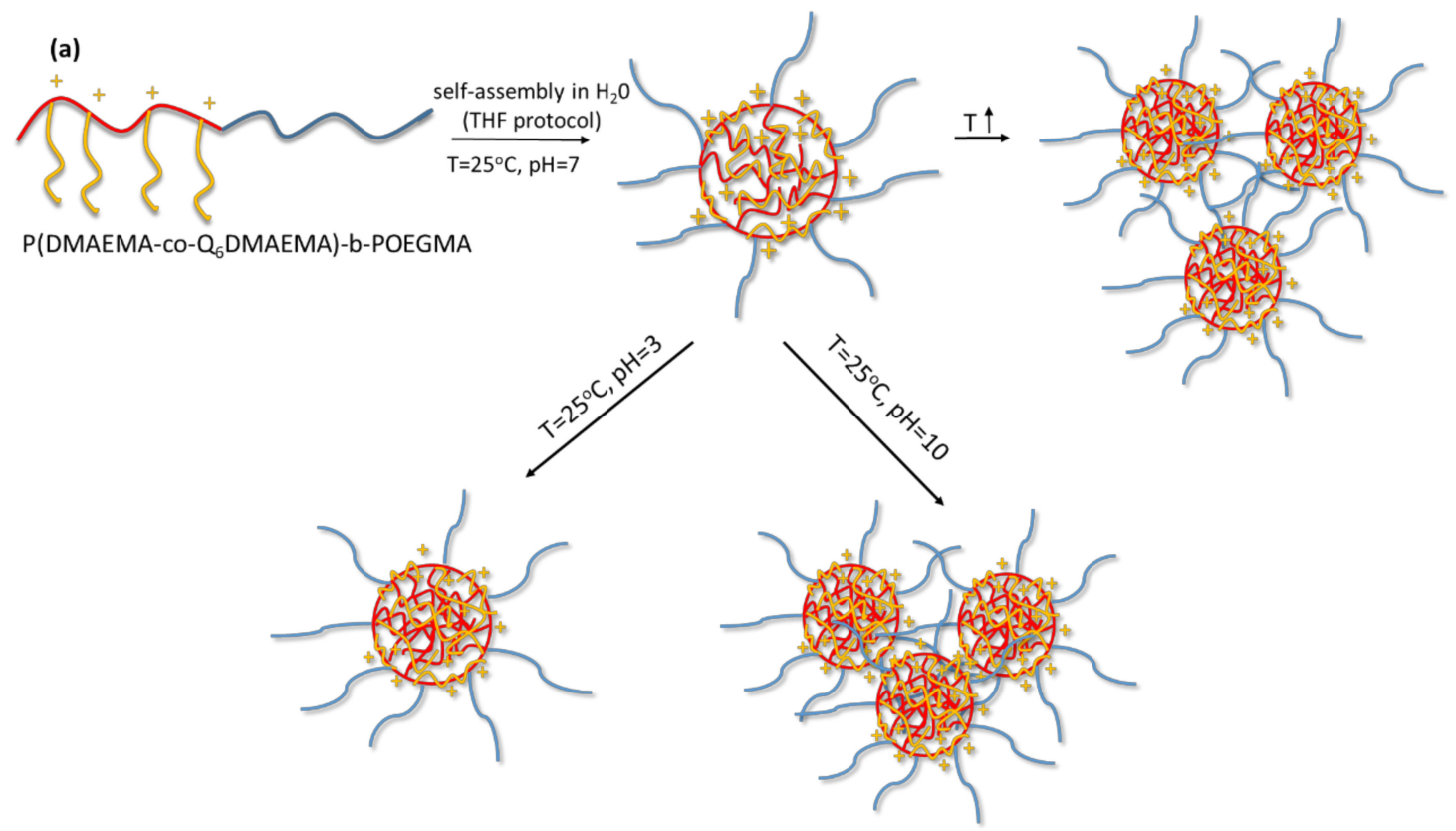

(b)
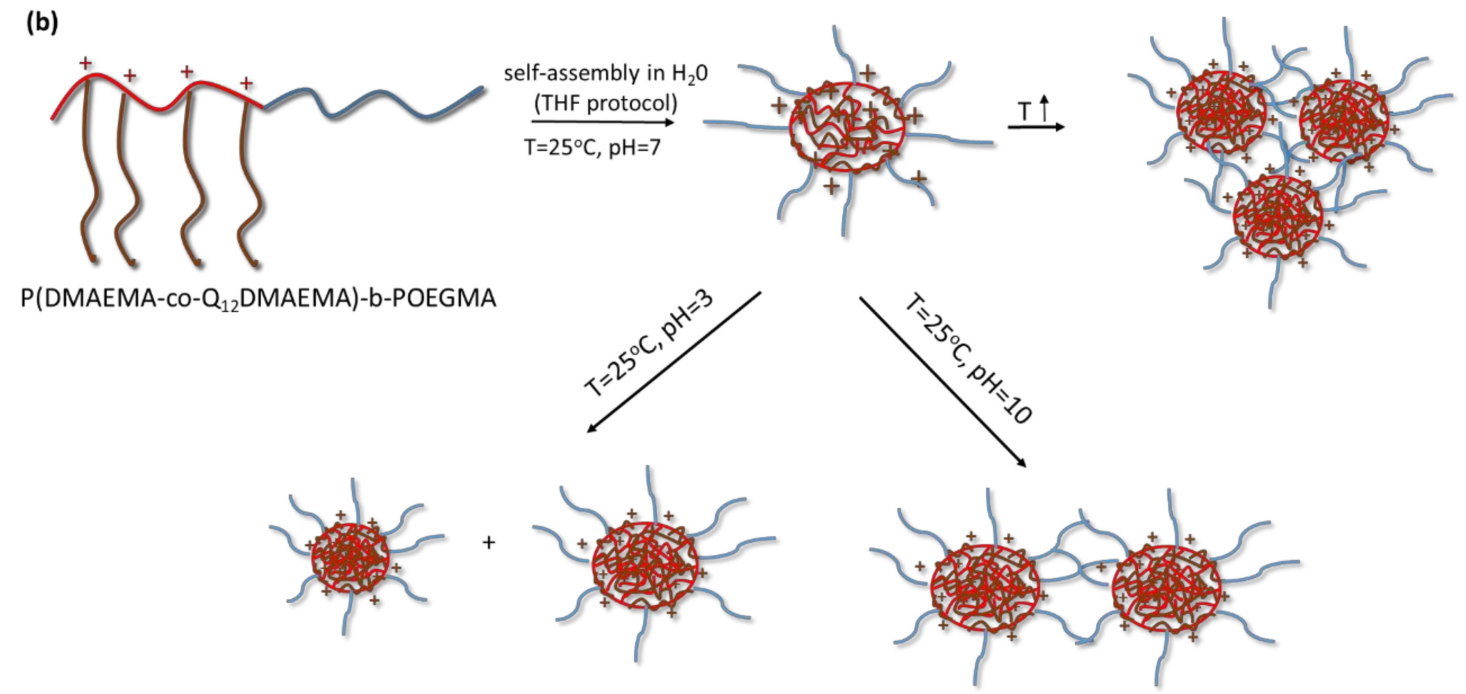

Scheme 2. Graphical illustration of the $\mathrm{pH}$ and temperature response of the aqueous solutions of (a) P(DMAEMA-co$\mathrm{Q}_{6}$ DMAEMA)- $b$-POEGMA and (b) P(DMAEMA-co-Q ${ }_{12}$ DMAEMA)- $b$-POEGMA diblocks, when the preparation protocol included the initial molecular dissolution of the copolymers in THF.

3.2.2. Temperature-Dependence of the Self-Assembly Behavior of the P(DMAEMA-Co-Q $6 /{ }_{12}$ DMAEMA)- $b$-POEGMA Random Diblock Copolymers

The temperature response of the random diblock copolymers was investigated, in the case of the aqueous solutions prepared by the organic solvent protocol at $1 \times 10^{-3} \mathrm{~g} / \mathrm{mL}$ concentration. 
Temperature Responsiveness of P(DMAEMA $30-$ CO-Q $_{6}$ DMAEMA $\left._{26}\right)-b$-POEGMA 86 and P(DMAEMA 28 -Co-Q ${ }_{12}$ DMAEMA $\left._{28}\right)$ - $b$-POEGMA 86

The partially quaternized samples, obtained from the first precursor diblock copolymer, with nominal quaternization degree ca. 20\% did not show significant thermoresponsive behavior. The observation is attributed to the surrounding of the thermoresponsive DMAEMA segments by the hydrophobic side chains that make difficult the phase transition of DMAEMA to less solvated/ dehydrated state (see Table S2).

Observations of the scattering intensity, of both samples as a function of temperature from $25{ }^{\circ} \mathrm{C}$ to $55^{\circ} \mathrm{C}$, which indicates alterations in the mass of the resulted nanostructures, confirmed the secondary aggregation as temperature increases (Figure 7a). Specifically, for both diblocks the transition temperature to a more hydrophobic/ dehydrated state is above $40^{\circ} \mathrm{C}$. However, the two samples do not follow the same tendency regarding the size of the formed aggregates. The size of the $2 \mathrm{Q}_{6}$ aggregates decreases as temperature increases, probably due to the destruction of the hydrogen bonds between the DMAEMA segments and water molecules and thus intermolecular polymer interactions dominate. On the other hand, the size of the $2 Q_{12}$ aggregates versus temperature appears rather constant (Figure 7b). A single population of nanoparticles, exists within the examined temperature range for both diblock solutions. This is confirmed by the size distributions from CONTIN, at $\mathrm{T}=25^{\circ} \mathrm{C}$ and $45^{\circ} \mathrm{C}$, where a monomodal peak appears (Figure $7 \mathrm{c}, \mathrm{d}$ ). All investigated solutions show high size homogeneity (PDI $\leq 0.2$ ) within the examined temperature range.

(a)

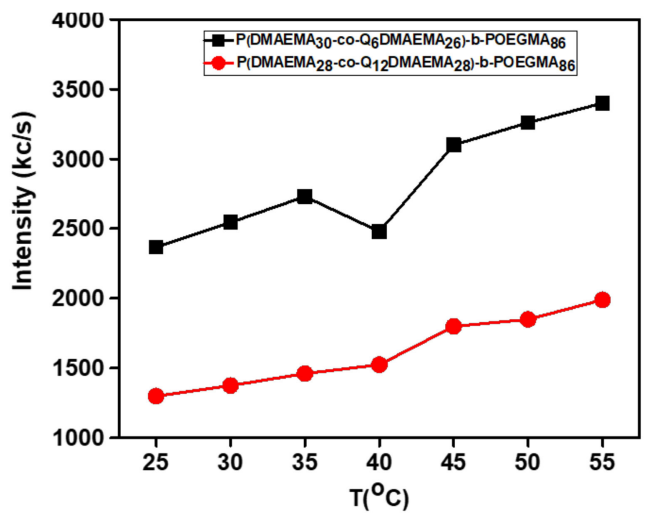

(c)

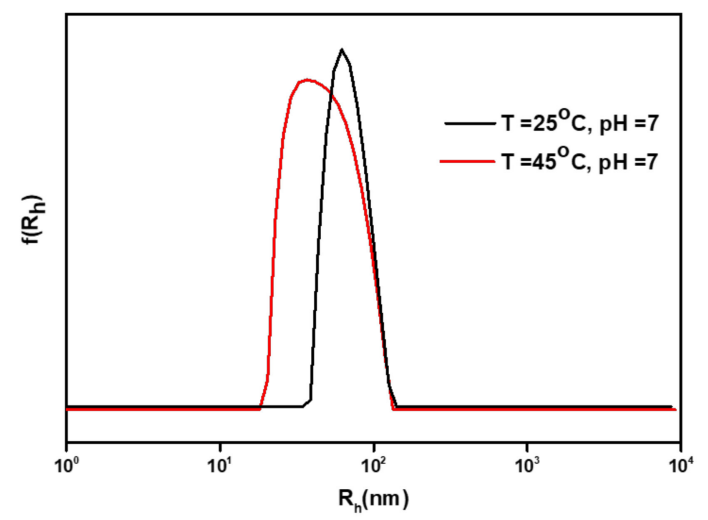

(b)

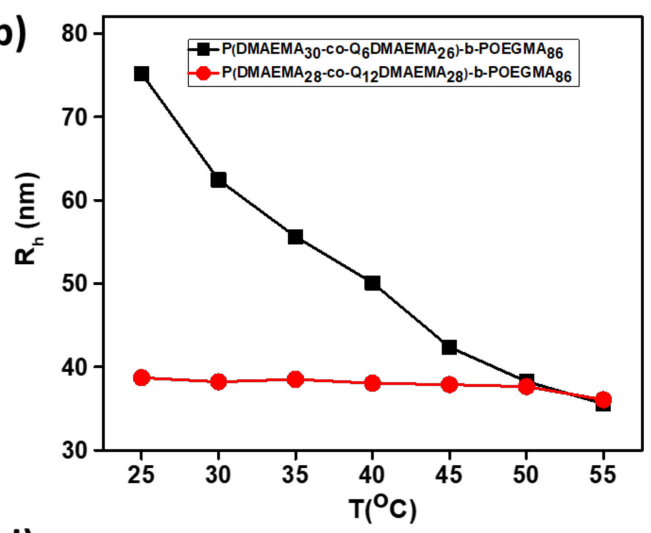

(d)

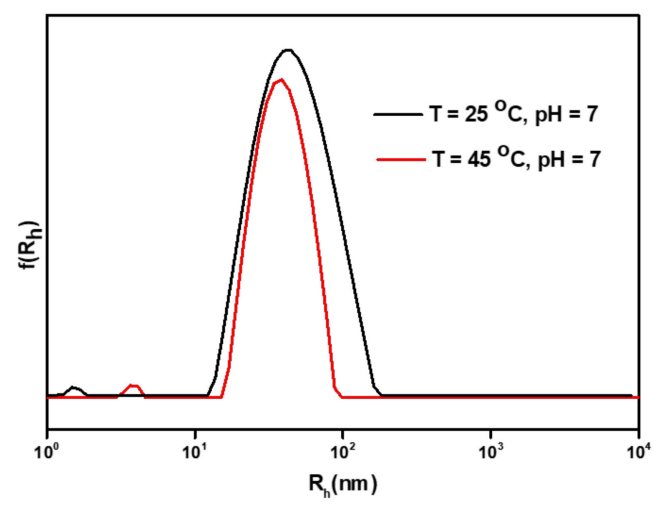

Figure 7. Dependence of (a) scattering intensity, (b) hydrodynamic radius for the P(DMAEMA $\left.30-\mathrm{CO}_{2}-\mathrm{Q}_{6} \mathrm{DMAEMA}_{26}\right)-b$ POEGMA $_{86}$ and $\mathrm{P}\left(\mathrm{DMAEMA}_{28}-\mathrm{CO}-\mathrm{Q}_{12} \mathrm{DMAEMA}_{28}\right)-b$-POEGMA 86 diblocks on temperature and size distributions from CONTIN obtained at $90^{\circ}$ measurement angle, at $\mathrm{T}=25^{\circ} \mathrm{C}, \mathrm{pH}=7$ and at $\mathrm{T}=45^{\circ} \mathrm{C}$ (for (c) $\mathrm{P}\left(\mathrm{DMAEMA}_{30}-\mathrm{CO}_{-} \mathrm{Q}_{6} \mathrm{DMAEMA}_{26}\right.$ )-

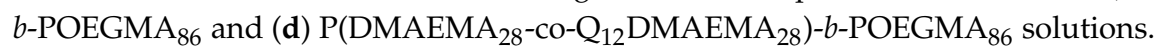


Temperature Responsiveness of P(DMAEMA ${ }_{22}-$ Co- $_{6}$ DMAEMA $\left._{20}\right)-b-$ POEGMA $_{12}$ and P(DMAEMA 21 -Co-Q ${ }_{12}$ DMAEMA $_{21}$ )- $b$-POEGMA 12 Diblocks

Investigations over the temperature response of the derivatives from the PDMAEMA $44^{-}$ $b$-POEGMA 12 diblock precursor were conducted only in the case the nominal quaternization degree was $50 \%$ (Figure 8), because it is anticipated that the amplified hydrophobic character compared with the random copolymers that contain less hydrophobic chains, would lead to immediate temperature response.

(a)

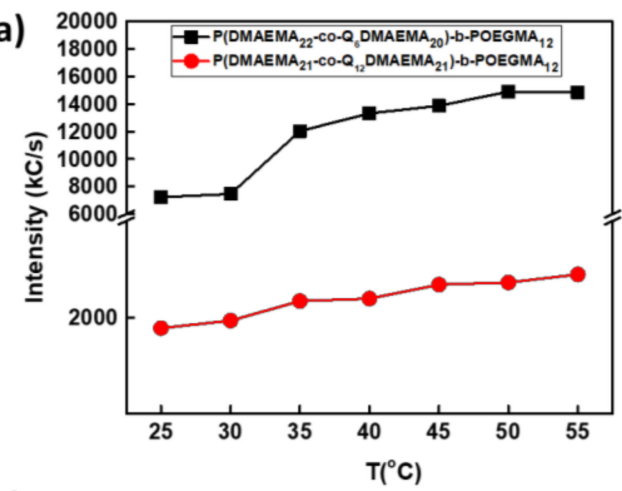

(c)

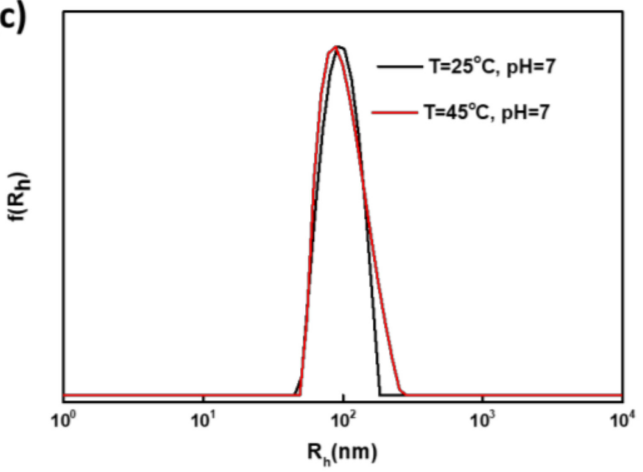

(b)

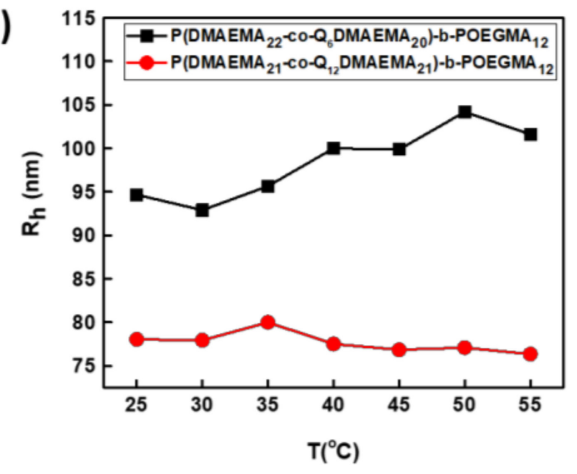

(d)

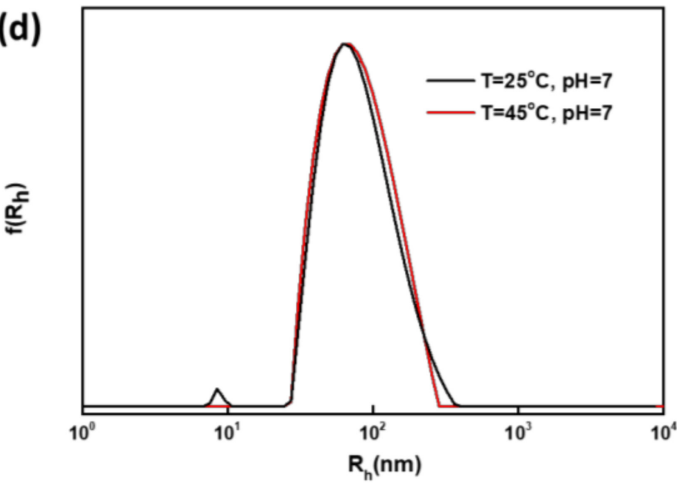

Figure 8. Dependence of (a) scattering intensity, (b) hydrodynamic radius for the P(DMAEMA $\left.22-\mathrm{CO}_{2}-\mathrm{Q}_{6} \mathrm{DMAEMA}_{20}\right)-b$ POEGMA $_{12}$ and $\mathrm{P}\left(\mathrm{DMAEMA}_{21}-\mathrm{Co}-\mathrm{Q}_{12} \mathrm{DMAEMA}_{21}\right)-b$-POEGMA 12 diblock solutions on temperature increase and size distribution from CONTIN obtained at $90^{\circ}$ measurement angle, at $\left.\mathrm{T}=25^{\circ} \mathrm{C}, \mathrm{pH}=7\right)$ and at $\mathrm{T}=45^{\circ} \mathrm{C}$ for $(\mathrm{c}) \mathrm{P}\left(\mathrm{DMAEMA}_{22}-\right.$ co-Q ${ }_{6}$ DMAEMA $\left._{21}\right)-b$-POEGMA 12 and (d) P(DMAEMA $21-$-co-Q ${ }_{12}$ DMAEMA $\left._{28}\right)-b$-POEGMA 12 .

The aforementioned hypothesis is confirmed in the case of diblock $4 \mathrm{Q}_{6}$, taking into account the dependence of the scattering intensity as temperature rises. The transition to a more hydrophobic/dehydrated state occurs at temperatures above $30^{\circ} \mathrm{C}$. The existence of more hydrophobic chains results in the transition to a less solvated state at a decreased temperature compared to sample $2 \mathrm{Q}_{6}$. It is worth mentioning that this comparison is qualitative even though both samples bear the same hydrophobic component (alkyl chain of six carbon atoms), but they are derived from diblocks that differ in PDMAEMA and POEGMA content. Subsequently, it is rather expected to behave differently towards temperature changes. The increase in the scattering intensity is accompanied with a small increase in hydrodynamic radius as secondary aggregation driven by the temperature rise results in nanoaggregates of both higher mass density and dimensions. The secondary aggregation is supported by the increase in the aggregation number from $25^{\circ} \mathrm{C}$ to $45^{\circ} \mathrm{C}$. The monomodal hydrodynamic size distribution depicted in the size distribution graphs at both temperatures indicates the existence of only one population of aggregates, prompting to the conclusion that the aggregation tendency as temperature rises is similar. The weak thermoresponsive behavior is assigned to the large hydrophobic contribution of alkyl chains of twelve carbon atoms that surround the DMAEMA segments and do not permit further intramolecular interactions between the DMAEMA parts along the polymeric chain. 
$\mathrm{R}_{\mathrm{g}} / \mathrm{R}_{\mathrm{h} 0}$ ratios for the $4 \mathrm{Q}_{6}$ sample obtained at $25^{\circ} \mathrm{C}$ and $45^{\circ} \mathrm{C}$, indicate the formation of compact spherical vesicles (Table 5). The high $\zeta$-potential values are in complete agreement with the large number of cations attached to QDMAEMA segments, some of which are presumably oriented towards the surface of the particles. Increase in temperature causes conformational alterations. Therefore, more cations compared with $\mathrm{T}=25^{\circ} \mathrm{C}$, are located on the surface of the particles and the value of the surface charge almost doubles. The nonthermoresponsive behavior of the $4 \mathrm{Q}_{12}$ is also verified by ELS measurements, as the surface charge remains essentially the same at both recorded temperatures. The higher value of the $4 Q_{12}$ aggregates compared to $4 Q_{6}$ ones may correspond to different inner morphology of the particles (Table 6).

Table 5. Physicochemical characteristics of the P(DMAEMA $\left.{ }_{30}-\mathrm{CO}_{-} \mathrm{Q}_{6} \mathrm{DMAEMA}_{26}\right)-b-\mathrm{POEGMA}_{86}$ and $\mathrm{P}\left(\mathrm{DMAEMA}_{28}-\right.$ $\mathrm{CO}-\mathrm{Q}_{12} \mathrm{DMAEMA}_{28}$ )- $b$-POEGMA 86 diblocks at two temperatures in solutions prepared by the organic solvent protocol $\left(\mathrm{c}=1 \times 10^{-3} \mathrm{~g} / \mathrm{mL}\right)$.

\begin{tabular}{|c|c|c|c|c|c|c|}
\hline Sample & $\begin{array}{l}\text { Quaternization } \\
\text { Degree (\%) }\end{array}$ & $\begin{array}{c}\mathrm{T} \\
\left({ }^{\circ} \mathrm{C}\right)\end{array}$ & $\begin{array}{c}R_{h} b, e \\
(\mathrm{~nm})\end{array}$ & PDI $^{b}$ & $\mathrm{~N}_{\text {agg }}{ }^{\mathrm{c}, \mathrm{e}}$ & $\begin{array}{c}\zeta_{\mathrm{p}} \\
\mathrm{d}, \mathrm{e}(\mathrm{mV})\end{array}$ \\
\hline 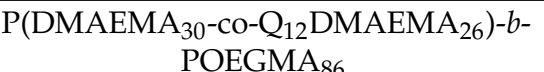 & \multirow{2}{*}{46} & 25 & 68 & 0.195 & 85 & +15.2 \\
\hline$\left(2 \mathrm{Q}_{6}\right)$ & & 45 & 45 & 0.173 & 103 & +19 \\
\hline $\begin{array}{c}\left.\text { P(DMAEMA }{ }_{28}-\text { CO- }_{12} \text { DMAEMA }_{28}\right)-b- \\
\text { POEGMA }_{86}\end{array}$ & \multirow{2}{*}{50} & 25 & 45 & 0.20 & 79 & +28 \\
\hline$\left(2 \mathrm{Q}_{12}\right)$ & & 45 & 38 & 0.192 & 91 & +35 \\
\hline
\end{tabular}

${ }^{\mathrm{a}}$ Determined by ${ }^{1} \mathrm{H}-\mathrm{NMR},{ }^{\mathrm{b}}$ Determined by DLS at measuring angle $90^{\circ},{ }^{\mathrm{c}}$ Determined by SLS, ${ }^{\mathrm{d}}$ Determined by ELS, ${ }^{\mathrm{e}}$ Values of $\mathrm{R}_{\mathrm{h}}, \mathrm{N}_{\mathrm{agg}}$ and $\zeta_{p}$ were determined with a standard deviation of $\pm 5 \%$. Note: The two different $R h$ values correspond to two different populations detected in the solution. The smaller one (fist value) is assigned to unimers, while the bigger one (second value) is assigned to aggregates. The difference in aggregation numbers at $\mathrm{T}=25^{\circ} \mathrm{C}$ and $45^{\circ} \mathrm{C}$, also confirms the further aggregation phenomena that occur because of the increased hydrophobic character induced by the temperature increase. ELS investigations showed increase of the surface charge for both diblocks when temperature increases from $25^{\circ} \mathrm{C}$ to $45^{\circ} \mathrm{C}$. The latter observation corresponds to morphological changes that arise as temperature increases, promoting a higher number of positive charges near the particle surface, also as a result of the increased number of chains per aggregate.

Table 6. Physicochemical characteristics of $\mathrm{P}\left(\mathrm{DMAEMA}_{22}-\mathrm{co}-\mathrm{Q}_{6} \mathrm{DMAEMA}_{20}\right)-b$-POEGMA 12 and $\mathrm{P}\left(\mathrm{DMAEMA}{ }_{21}-\mathrm{co}-\right.$ $\mathrm{Q}_{12}$ DMAEMA $_{21}$ )- $b$-POEGMA 12 diblock solutions prepared by the organic solvent protocol $\left(c=1 \times 10^{-3} \mathrm{~g} / \mathrm{mL}\right.$, at two different temperatures.

\begin{tabular}{|c|c|c|c|c|c|c|c|}
\hline Sample & $\begin{array}{l}\text { Quaternization } \\
\text { degree }(\%)^{a}\end{array}$ & $\begin{array}{c}\mathrm{T} \\
\left({ }^{\circ} \mathrm{C}\right)\end{array}$ & $\begin{array}{l}R_{h} b, e \\
(n m)\end{array}$ & PD.I ${ }^{b}$ & $\mathbf{N}_{\text {agg }}{ }^{c, e}$ & $\underset{b, c}{R_{g} / R_{h 0}}$ & $\begin{array}{l}\zeta_{\mathrm{p}} \mathrm{d}, \mathrm{e} \\
(\mathrm{mV})\end{array}$ \\
\hline \multirow{2}{*}{$\begin{array}{c}\mathrm{P} \text { DMAEMA }_{30} \text {-co- } \\
\left.\mathrm{Q}_{12} \text { DMAEMA }_{26}\right)-b-\text { POEGMA }_{86} \\
\left(4 \mathrm{Q}_{6}\right)\end{array}$} & \multirow{2}{*}{48} & 25 & 95 & 0.128 & 145 & 0.99 & +26.1 \\
\hline & & 45 & 100 & 0.126 & 279 & 0.9 & +46.5 \\
\hline \multirow{2}{*}{$\begin{array}{c}\mathrm{P}\left(\mathrm{DMAEMA}_{28} \text {-co- }\right. \\
\left.\mathrm{Q}_{12} \text { DMAEMA }_{28}\right)-b \text {-POEGMA } \\
\left(4 \mathrm{Q}_{12}\right)\end{array}$} & \multirow{2}{*}{50} & 25 & 78 & 0.229 & 83 & 0.64 & +54.3 \\
\hline & & 45 & 66 & 0.215 & 87 & 1.06 & +58.4 \\
\hline
\end{tabular}

${ }^{\text {a }}$ Determined by ${ }^{1} \mathrm{H}-\mathrm{NMR},{ }^{\mathrm{b}}$ Determined by DLS at measuring angle $90^{\circ},{ }^{\mathrm{c}}$ Determined by SLS, ${ }^{\mathrm{d}}$ Determined by ELS, ${ }^{\mathrm{e}}$ Values of $\mathrm{R}_{\mathrm{h}}, \mathrm{N}_{\mathrm{agg}}$ and $\zeta_{p}$ were determined with a standard deviation of $\pm 5 \%$.

\subsection{Encapsulation and Release Studies of Indomethacin}

One of the most interesting and studied applications of the amphiphilic block copolymers is the encapsulation of hydrophobic drugs. Random diblock copolymers were not so appealing for encapsulating hydrophobic drugs, before due to the inconsistency of the components along the polymeric chain. In the case of $\mathrm{P}\left(\mathrm{DMAEMA}-\mathrm{co}-\mathrm{Q}_{6 / 12} \mathrm{DMAEMA}\right)-$ $b$-POEGMA block copolymers, the presence of long alkyl side chains enhances the hydrophobic character of the polymeric system and the inner region of aggregates formed in aqueous media should be structured by the random block where DMAEMA and QD- 
MAEMA segments are segregated in a "scrambled egg" fashion. Subsequently, the inner aggregate region includes hydrophobic nano-domains formed by the aggregation of the long alkyl side chains, which can be used for the accommodation of hydrophobic drugs. Along with the rather biocompatible nature of the components of the block copolymers under study and their stimuli response, the random block copolymers are expected to be suitable nanomaterials for the encapsulation and delivery of the model hydrophobic drug indomethacin. From the eight random diblock copolymers synthesized, four were chosen for the encapsulation studies involving indomethacin, namely, the ones of nominal 50\% quaternization degree due to their amplified hydrophobic character. The weight ratios (theoretical encapsulation degrees) of IND, relative to the entire random diblock copolymer was $10 \%$ and $20 \%$ wt. For brevity, the mixed samples would be referred as P(DMAEMA-co- ${ }_{6 / 12}$ DMAEMA)-b-POEGMA/IND10\% and P(DMAEMA-co$\mathrm{Q}_{6 / 12}$ DMAEMA)-b-POEGMA/IND20\% respectively, according to the length of the alkyl chain and the weight composition of each mixture. DLS and SLS techniques were implemented to determine the mass, morphology and size of mixed nanoaggregates, and UV-Vis spectrophotometry for the assessment of the drug-loading efficiency. The obtained results are presented in Table 7.

Table 7. Physicochemical characteristics of the mixed random diblock copolymers with IND and the drug loading results of all the examined mixed nanoparticles.

\begin{tabular}{|c|c|c|c|c|c|c|}
\hline Sample & $\begin{array}{c}\text { Stoichiometry of } \\
\text { Encapsulation a } \\
(\% w / w)\end{array}$ & $\begin{array}{l}\text { Intensity } \\
\mathrm{b}, \mathrm{f}(\mathrm{kC} / \mathrm{s})\end{array}$ & $\begin{array}{l}R_{h} c, f \\
(n m)\end{array}$ & $\mathbf{R}_{\mathrm{g}} / \mathbf{R}_{\mathrm{h} 0} \mathrm{~b}$ & $\begin{array}{l}\% \text { Drug } \\
\text { loading d,f }\end{array}$ & $\begin{array}{l}\zeta_{p}{ }^{e, f} \\
(m V)\end{array}$ \\
\hline $\begin{array}{c}\text { P(DMAEMA }{ }_{30-\mathrm{co}-} \\
\left.\mathrm{Q}_{6} \mathrm{DMAEMA}_{26}\right)-b- \\
\text { POEGMA }_{86} / \mathrm{IND}^{2} \%\end{array}$ & 10 & 872 & 125.17 & 0.55 & 5.5 & +21 \\
\hline $\begin{array}{c}\text { P(DMAEMA }{ }_{28}-\text { CO- } \\
\left.\text { Q }_{12} \text { DMAEMA }_{28}\right)-b- \\
\text { POEGMA }_{86} / \text { IND }^{2} \%\end{array}$ & 10 & 2990 & 82.25 & 0.75 & 4 & +11.5 \\
\hline $\begin{array}{c}\text { P(DMAEMA }{ }_{22}-\mathrm{CO}- \\
\left.\text { Q }_{6} \text { DMAEMA }_{20}\right)-b- \\
\text { POEGMA }_{12} / \text { IND }^{2} \%\end{array}$ & 10 & 1654 & 121.97 & 0.63 & 3 & +45 \\
\hline $\begin{array}{c}\text { P(DMAEMA }{ }_{21} \text {-co- } \\
\left.\text { Q }_{12} \text { DMAEMA }_{21}\right)-b- \\
\text { POEGMA }_{12} / \text { IND } 10 \%^{2}\end{array}$ & 10 & 1456 & 102.06 & 0.5 & 6 & +44.6 \\
\hline $\begin{array}{c}\text { P(DMAEMA }{ }_{30-\text { co- }} \\
\left.\text { Q }_{6} \text { DMAEMA }_{26}\right)-b- \\
\text { POEGMA }_{86} / \text { IND20\% }^{2}\end{array}$ & 20 & 2555 & 106.86 & 0.5 & 7.2 & +28 \\
\hline $\begin{array}{c}\text { P(DMAEMA }{ }_{28}-\mathrm{CO}- \\
\left.\text { Q }_{12} \text { DMAEMA }_{28}\right)-b- \\
\text { POEGMA }_{86} / \text { IND20\% }^{2} \%\end{array}$ & 20 & 32000 & 93.15 & 0.84 & 7 & +23 \\
\hline $\begin{array}{c}\text { P(DMAEMA }{ }_{22}-\mathrm{CO}- \\
\left.\text { Q }_{6} \text { DMAEMA }_{20}\right)-b- \\
\text { POEGMA }_{12} / \text { IND20\% }^{2} \%\end{array}$ & 20 & 2570 & 113.22 & 0.5 & 5.5 & +52 \\
\hline $\begin{array}{c}\text { P(DMAEMA }{ }_{21} \text {-co- } \\
\left.\text { Q }_{12} \text { DMAEMA }_{21}\right)-b- \\
\text { POEGMA }_{12} / \text { IND } 20 \%^{2}\end{array}$ & 20 & 1950 & 94.30 & 0.53 & 6.3 & +50 \\
\hline
\end{tabular}

${ }^{a}$ Calculated according to the amount of the copolymer, used ${ }^{b}$ Determined by DLS at measuring angle $90^{\circ},{ }^{c}$ Determined by SLS,

${ }^{\mathrm{d}}$ Determined by calculating the ratio of IND weight in the nanoparticles, based on UV-Vis absorption values, to the weight of the used IND, ${ }^{\mathrm{e}}$ Determined by ELS, ${ }^{\mathrm{f}}$ Values were determined with a standard deviation of $\pm 5 \%$.

An important observation, however is that the size of the mixed nanoparticles are larger than that of unloaded ones, indicating that the incorporation of IND into the inner hydrophobic domains contributes to the formation of larger polymer/drug aggregates. 
Moreover, the high scattered intensity measured is attributed to the formation of mixed nanoaggregates of high mass. The drug loading efficiency results are satisfactory although optimization of the encapsulation process is of the essence before stepping into real drug-delivery applications. Higher drug loading is obtained when higher initial drug quantity was used. From this observation the case of $\mathrm{P}\left(\mathrm{DMAEMA}_{22}-\mathrm{Co}-\mathrm{Q}_{6} \mathrm{DMAEMA}_{20}\right)$ $b$-POEGMA $A_{12} /$ IND$^{2} \%$ is excluded probably due to structural features of the formed aggregates that do not favour the encapsulation of IND. In addition, a comparison on the drug loading efficiency should be performed according to the used quaternization agent along with the precursor diblock copolymer characteristics. When the PDMAEMA ${ }_{56}{ }^{-b-}$ POEGMA $_{86}$ copolymer was partially quaternized with iodohexane, higher drug loading (compared with the theoretical encapsulation values) were determined, denoting that the iodohexane functionalized diblock functions as a better encapsulation agent. On the other hand, when the PDMAEMA $44-b$-POEGMA 12 diblock was partially quaternized with iodododecane, higher drug loading was obtained, demonstrating that the iodododecane acts as more appropriate encapsulation agent. It may be concluded that molecular characteristics of the initial diblocks and nature of quaternization agent play a significant role in random block copolymer/IND interactions and drug encapsulation. The aforementioned conclusion is also supported by the size distributions (Figure 9) that demonstrate higher sizes of the mixed nanoassemblies when the PDMAEMA ${ }_{56}-b-$ POEGMA $_{86}$ was quaternized with iodohexane and the PDMAEMA $44-b$-POEGMA 12 was quaternized with iodododecane, for the same nominal quaternization degree. A possible explanation of the abovementioned observation is the encapsulation of higher drug quantity in these cases.

(a)

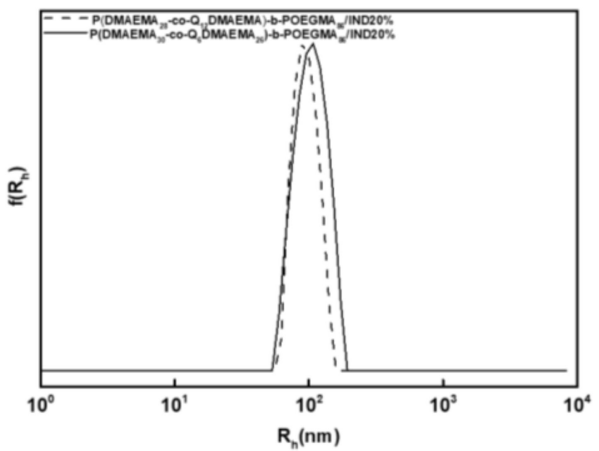

(b)

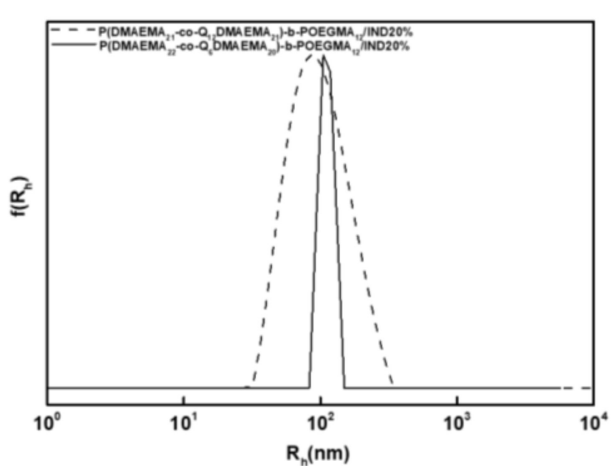

Figure 9. Size distributions from CONTIN for the mixed nanoassemblies resulting by the combination of IND at $20 \%$ and (a) partially quaternized PDMAEMA 56 - $b$-POEGMA 86 with iodohexane and iodododecane and (b) partially quaternized PDMAEMA $_{44}-b$-POEGMA 12 with iodohexane and iodododecane.

In all cases monodisperse size distributions appear, confirming that one population of particles are dispersed in the aqueous media, which is desirable for drug delivery applications. Moreover, the higher POEGMA composition seems to contribute in the encapsulation of larger amount of IND due to better colloidal stability and increased solvation of the drug loaded aggregates.

The interactions existing between the encapsulated IND and the random diblock

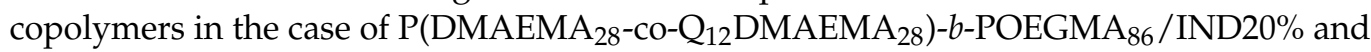
P(DMAEMA ${ }_{21}$-co- ${ }_{12}$ DMAEMA $\left._{21}\right)-b$-POEGMA $12 /{ }_{1 N D 20} \%$ assemblies were studied by ATR-FTIR spectroscopy (Figure 10). 


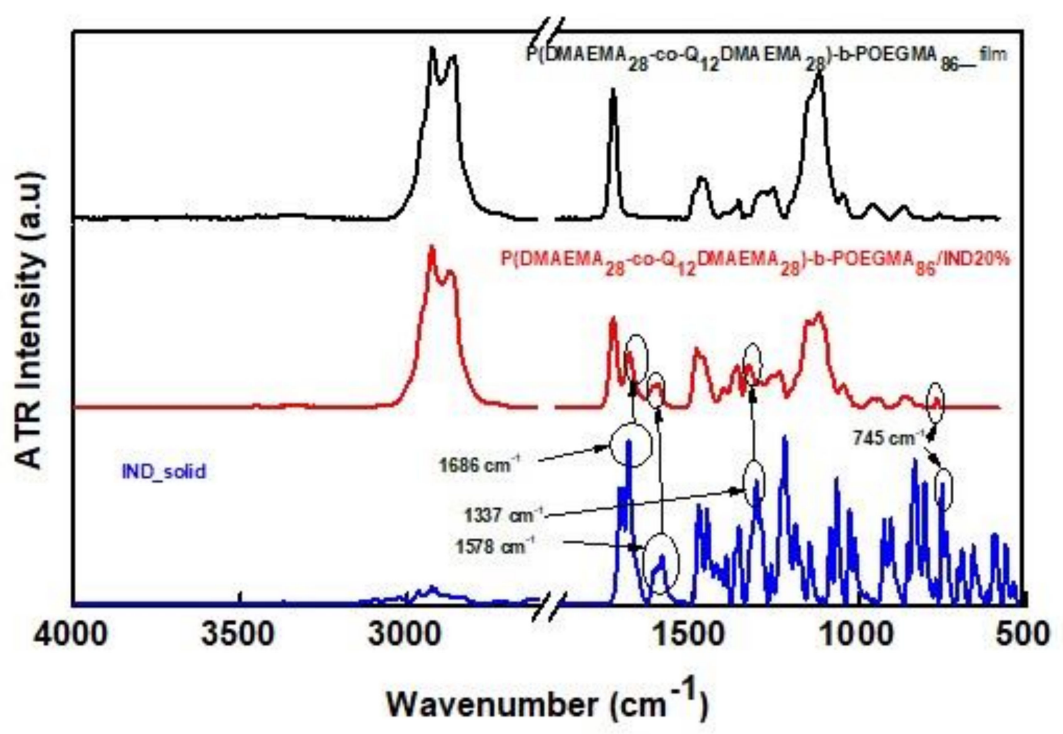

Figure 10. Comparative ATR-FTIR spectra of the mixed P(DMAEMA $\left.28-\mathrm{CO}_{2}-\mathrm{Q}_{12} \mathrm{DMAEMA}_{28}\right)-b$ POEGMA $_{86} /$ IND20\% aggregates the P(DMAEMA $28-{ }_{20}-Q_{12}$ DMAEMA $\left._{28}\right)$ - $b$-POEGMA P $_{86}$ empty aggregates and IND in the solid state.Note: The ATR-FTIR spectra of aqueous solutions of random diblock copolymer and mixed nanoassemblies of random diblock copolymer with IND emanated after the evaporation of water by using nitrogen, so that the water absorption peaks would not intervene with the characteristic absorption peaks that would reveal the interactions between IND and the random diblock copolymer.

The spectra of the mixed P(DMAEMA $21-$-co-Q ${ }_{12}$ DMAEMA $\left._{21}\right)-b$-POEGMA $12 /$ IND20 $_{1}$ aggregates with the $\mathrm{P}\left(\mathrm{DMAEMA}_{21}-\mathrm{CO}^{-} \mathrm{Q}_{12} \mathrm{DMAEMA}_{21}\right)-b$-POEGMA ${ }_{12}$ empty aggregates are presented in the SI (Figure S6). Those two samples were selected to be investigated by ATR-FTIR because they present the higher loading efficiency and the physical interactions between vectors and IND would be stronger and more easily identifible.

Regarding the ATR-FTIR spectrum of solid indomethacin, the characteristic absorption band at $1686 \mathrm{~cm}^{-1}$ is assigned to amide I group and specifically to the stretching vibration of the $\mathrm{C}=\mathrm{O}$ group, the one at $1578 \mathrm{~cm}^{-1}$ is assigned to $\mathrm{C}=\mathrm{C}$ stretching vibration of the aromatic rings. Moreover, the absorption peak at $1337 \mathrm{~cm}^{-1}$ is assigned to the asymmetric stretching of the $\mathrm{C}$-O group and the one at $745 \mathrm{~cm}^{-1}$ corresponds to the $\mathrm{C}-\mathrm{Cl}$ stretching vibration $[65,66]$.

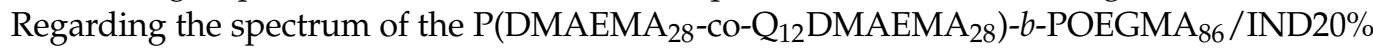
mixed aqueous solution, the characteristic IND absorption peaks appear, indicating the strong physical interactions between $\mathrm{P}\left(\mathrm{DMAEMA}_{28}-\mathrm{Co}^{-} \mathrm{Q}_{12} \mathrm{DMAEMA}_{28}\right)-b-\mathrm{POEGMA}_{86}$ diblock and the encapsulated IND. The absence of these characteristic absorption peaks in the ATR-FTIR spectrum of the $\mathrm{P}\left(\mathrm{DMAEMA}_{21}-\mathrm{co}-\mathrm{Q}_{12} \mathrm{DMAEMA}_{21}\right)-b$-POEGMA ${ }_{12}$ diblock (black line) confirms the encapsulation of IND into the polymeric nanoaggregates.

The release of IND from $\mathrm{P}\left(\mathrm{DMAEMA}_{28}-\mathrm{co}-\mathrm{Q}_{12} \mathrm{DMAEMA}_{28}\right)-b$-POEGMA $\mathrm{P}_{86}$ containing nanoaggregates under sonication, is presented in Figure 11. 


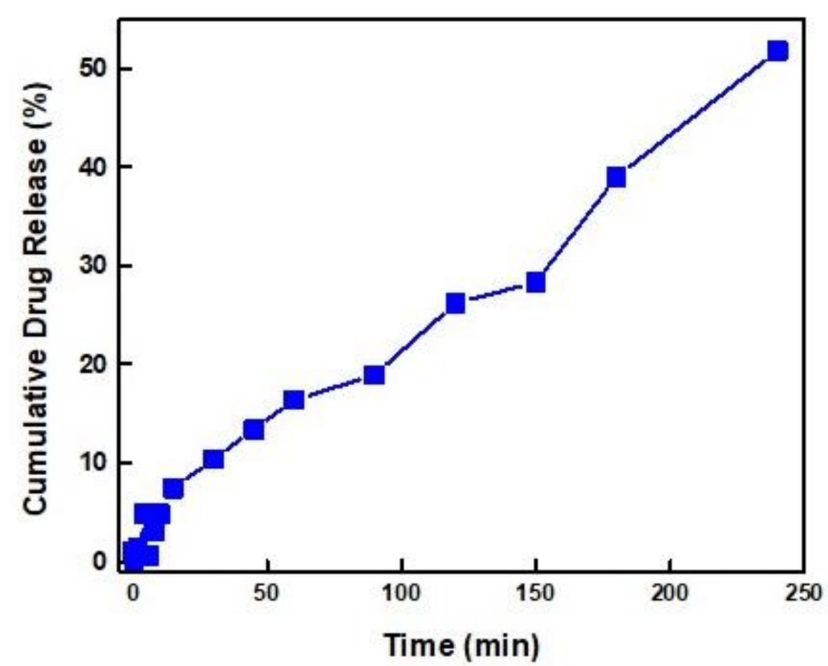

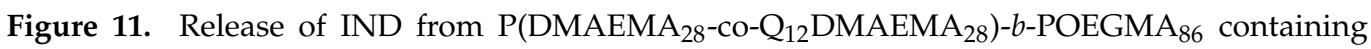
nanoaggregates under sonication.

Drug release studies were performed at the $\mathrm{P}\left(\mathrm{DMAEMA}_{28}-\mathrm{Co}-\mathrm{Q}_{12} \mathrm{DMAEMA}_{28}\right)-b-$ POEGMA $_{86} /$ IND20\% sample. The specific nanosystem was chosen due to the high drug loading efficiency, the high aggregate mass (determined by the high scattering intensity value) and the good colloidal stability over time (more than 15 days) that this sample exhibited due to the good solubility characteristics that the high POEGMA content provide. Initially, release studies were performed at sink conditions at room temperature. $\mathrm{tNo}$ appreciable release of IND was observed for $12 \mathrm{~h}$. The release studies were performed using an ultrasonic bath in order to aid the release of IND. The absorbance of each sample was recorded by UV-Vis spectrophotometer in pre-defined time intervals. The highest rate of IND release was monitored after $4 \mathrm{~h}$ since the beginning of the ultrasonication process and determined to be almost $50 \%$. It was also noticed that the release of indomethacin starts almost at the same time with the application of ultrasonic radiation and it is constantly increasing throughout the release experiment, which lasted for four hours, without reaching a plateau. The relatively high IND release implies that a great portion of the indomethacin is not tightly bound to the polymeric nanoaggregates and it is more easily released. However, the intensity of the formed interactions between drug and polymer is adequate in order to retain the indomethacin encapsulated in the polymeric nanoaggregates in the absence of sonication, which in turn allows for an externally triggered and controlled release of the drug from the particular random block copolymer nanocarriers.

\section{Conclusions}

Novel random diblock copolymers were prepared via partial hydrophobic chemical modification of PDMAEMA- $b$-POEGMA precursor double hydrophilic diblock copolymers, which were synthesized by RAFT polymerization. The quaternization agents utilized were iodohexane and iodododecane. The molecular characterization methods confirmed the synthesis of relatively well-defined block copolymers. The experimental quaternization degrees found by ${ }^{1} \mathrm{H}-\mathrm{NMR}$ were in accordance with the theoretical values calculated by using the molar ratio of the alkyl halide to the DMAEMA monomeric units during chemical functionalization. Light scattering techniques showed the formation of nanoaggregates of high mass along with relatively low size in aqueous media. The self-assembly of the random diblock copolymers that bear alkyl chains of twelve carbon atoms led to formation of nanoaggregates of lower mass due to the enhanced hydrophobic character of the polymeric chains. Unimolecular dissolved copolymer chains were also detected in some cases. The ability of the hydrophobically modified diblock copolymers to respond to $\mathrm{pH}$ and temperature changes remained, but it greatly depended on the quaternization degree, nature of the alkyl side chain and preparation protocol. Generally, nanoaggregates 
of the aqueous solutions prepared by implementing the organic solvent protocol (using THF) were better defined judging from their rather low polydispersity indexes, better colloidal stability over time and exhibited significant response to $\mathrm{pH}$ and temperature. The imparted hydrophobic character led to significantly lower transition temperature than the reported LCST of PDMAEMA homopolymer. In the case of P(DMAEMA ${ }_{30^{-}}$ Co- $_{12}$ DMAEMA $_{26}$ )- $b$-POEGMA 86 copolymer, when the preparation protocol included the use of organic solvent the $R_{g} / R_{h 0}$ parameter acquired values above 1 , indicating the possible formation of spherical vesicles. ELS investigations showed rather high positive surface charge assigned to the morphology of the nanoaggregates where the hydrophobic chains obtained such configuration that allows the positive charges to be located on the surface. The increase in the quaternization degree was accompanied with an increase in the surface charge. Subsequently, due to the increased hydrophobic character of the diblocks encapsulation studies of the inflammatory, hydrophobic drug indomethacin, was achieved. The resulted IND loaded nanoparticles were larger in size due to the hydrophobic nature of indomethacin. Drug loading efficiency studies showed the successful encapsulation of indomethacin. Indomethacin release experiments under sonication demonstrated the successful release of a high proportion of the drug. Overall, the side group nature and particular molecular characteristics of the hydrophobically modified P(DMAEMA-co$\mathrm{Q}_{6 / 12}$ DMAEMA)-b-POEGMA random diblock copolymers, along with their tunable $\mathrm{pH}$ and temperature response makes them another novel example of amphiphilic copolymers with controlled and unprecedented self-assembly characteristics and aggregate structure appealing for utilization in bionanotechnological applications, including drug, gene and protein delivery.

Supplementary Materials: The following are available online at https:/ /www.mdpi.com/2073-436 0/13/3/338/s1, Figure S1: SEC chromatograms of PDMAEMA 42 (first block) and PDMAEMA 42 - $b$ POEGMA $_{12}$ (final diblock copolymer), Figure S2: ${ }^{1} \mathrm{H}-\mathrm{NMR}$ spectrum for PDMAEMA 44 in $\mathrm{CDCl}_{3}$, Figure S3: Comparative ATR-FTIR spectra of (a) PDMAEMA ${ }_{56}-b$-POEGMA 86 precursor diblock copolymer (red line) and (b) P(DMAEMA ${ }_{45}-b$ - $\mathrm{Q}_{6}$ DMAEMA $\left._{11}\right)-b$-POEGMA 86 resulted random diblock copolymer (blue line), Figure S4: Dependence of (a) scattering intensity (I), (b) hydrodynamic

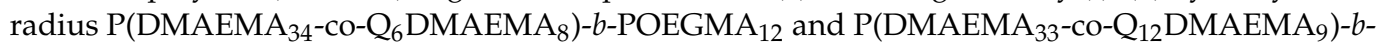
POEGMA $_{12}$ aqueous solutions on pH-variations (THF protocol), Figure S5: Dependence of (a) scattering intensity (I), (b) hydrodynamic radius $\mathrm{P}\left(\mathrm{DMAEMA}_{22}-\mathrm{co}^{-} \mathrm{Q}_{6} \mathrm{DMAEMA}_{20}\right)-b$-POEGMA 12 and $\mathrm{P}\left(\mathrm{DMAEMA}_{21}\right.$-co- $\mathrm{Q}_{12}$ DMAEMA $_{21}$ )- $b$-POEGMA 12 aqueous solutions on $\mathrm{pH}$-variations (THF protocol), Figure S6: Comparative ATR-FTIR spectra of the mixed P(DMAEMA 21 -co- ${ }_{12}$ DMAEMA $_{21}$ )$b$-POEGMA $12 /{\text { IND20 } \% \text { (black line), the P(DMAEMA }{ }_{21} \text {-co-Q }{ }_{12} \text { DMAEMA }_{21} \text { )- } b \text {-POEGMA }}_{12}$ empty vector (red line) and IND at solid state (blue line), Table S1: Scattering intensity and $R_{h}$ results for the random diblock copolymers, obtained by the partial quaternization of the PDMAEMA ${ }_{56}-b$ POEGMA 86 precursor, Table S2: Scattering intensity and $R_{h}$ results for the $1 Q_{6}$ and $1 Q_{12}$ samples at $\mathrm{T}=25{ }^{\circ} \mathrm{C}$ and $\mathrm{T}=45{ }^{\circ} \mathrm{C}$.

Author Contributions: S.P. and M.K. designed the experiments. M.K. conducted the experiments. S.P. contributed the materials/reagents and instrumentation and supervised the project. M.K. and S.P. analyzed the experimental data and wrote the manuscript. All authors have read and agreed to the published version of the manuscript.

Funding: The research work was supported by the Hellenic Foundation for Research and Innovation (HFRI) under the HFRI PhD Fellowship grant (Fellowship Number: 799).

Institutional Review Board Statement: Not applicable.

Informed Consent Statement: Not applicable.

Data Availability Statement: Data are available upon request. 
Conflicts of Interest: The authors declare no conflict of interest.

\section{References}

1. McCormick, C.; Sumerlin, B.; Lokitz, B.; Stempka, J. RAFT-synthesized diblock and triblock copolymers: Thermally-induced supramolecular assembly in aqueous media. Soft Matter 2008, 4, 1760-1773. [CrossRef]

2. York, A.W.; Kirkland, S.E.; McCormick, C.L. Advances in the synthesis of amphiphilic block copolymers via RAFT polymerization: Stimuli-responsive drug and gene delivery. Adv. Drug Deliv. Rev. 2008, 60, 1018-1036. [CrossRef] [PubMed]

3. Feng, H.; Lu, X.; Wang, W.; Kang, N.G.; Mays, J.W. Block Copolymers: Synthesis, Self-Assembly, and Applications. Polymers 2017, 9, 494. [CrossRef] [PubMed]

4. Mai, Y.; Eisenberg, A. Self-assembly of block copolymers. Chem. Soc. Rev. 2012, 41, 5969-5985. [CrossRef]

5. Kataoka, K.; Harada, A.; Nagasaki, Y. Block copolymer micelles for drug delivery: Design, characterization and biological significance. Adv. Drug Deliv. Rev. 2001, 47, 113-131. [CrossRef]

6. Cabral, H.; Miyata, K.; Osada, K.; Kataoka, K. Block Copolymer Micelles in Nanomedicine Applications. Chem. Rev. 2018, 118, 6844-6892. [CrossRef]

7. Mura, S.; Nicolas, J.; Couvreur, P. Stimuli-responsive nanocarriers for drug delivery. Nat. Mater. 2013, 12, 991-1003. [CrossRef]

8. Li, L.; Raghupathi, K.; Song, C.; Prasad, P.; Thayumanavan, S. Self-assembly of random copolymers. Chem. Comm. 2014, 50, 13417-13432. [CrossRef]

9. Hirai, Y.; Terashima, T.; Takenaka, M.; Sawamoto, M. Precision Self-Assembly of Amphiphilic Random Copolymers into Uniform and Self-Sorting Nanocompartments in Water. Macromolecules 2016, 49, 5084-5091. [CrossRef]

10. Matsumoto, K.; Terashima, T.; Sugita, T.; Takenaka, M.; Sawamoto, M. Amphiphilic Random Copolymers with Hydrophobic/ Hydrogen-Bonding Urea Pendants: Self-Folding Polymers in Aqueous and Organic Media. Macromolecules 2016, 49, 7917-7927. [CrossRef]

11. Kimura, Y.; Terashima, T.; Sawamoto, M. Self-Assembly of Amphiphilic Random Copolyacrylamides into Uniform and Necklace Micelles in Water. Macromol. Chem. Phys. 2017, 218, 1700230. [CrossRef]

12. Gohy, J.F. Block Copolymer Micelles. Advances in Polymer Science, Block Copolymers; Abetz, V., Ed.; Springer Nature: Cham, Switzerland, 2005; Volume 190, pp. 65-136.

13. Imai, S.; Hirai, Y.; Nagao, C.; Sawamoto, M.; Terashima, T. Programmed Self-Assembly Systems of Amphiphilic Random Copolymers into Size-Controlled and Thermoresponsive Micelles in Water. Macromolecules 2018, 51, 398-409. [CrossRef]

14. Guazzelli, E.; Martinelli, E.; Giancarlo, G.; Cupellini, L.; Jurinovich, S.; Mannucci, B. Single-chain self-folding in an amphiphilic copolymer: An integrated experimental and computational study. Polymer 2019, 161, 33-40. [CrossRef]

15. Matsumoto, M.; Terashima, T.; Matsumoto, K.; Takenaka, M.; Sawamoto, M. Compartmentalization Technologies via SelfAssembly and Cross-Linking of Amphiphilic Random Block Copolymers in Water. J. Am. Chem. Soc. 2017, 139, 7164-7167. [CrossRef] [PubMed]

16. Sanders, C.A.; Sean, G.R.; Deeter, G.A.; Campbell, J.D.; Reck, B.; Cunningham, M.F. Amphiphilic Block-Random Copolymers: Self-Folding Behavior and Stabilizers in Emulsion Polymerization. Macromolecules 2019, 52, 4510-4519. [CrossRef]

17. Gohy, J.-F.; Lohmeijer, B.G.G.; Varshney, S.K.; Décamps, B.; Leroy, E.; Boileau, S.; Schubert, U.S. Stimuli-Responsive Aqueous Micelles from an ABC Metallo-Supramolecular Triblock Copolymer. Macromolecules 2002, 35, 9748-9755. [CrossRef]

18. Alarcon, C.d.1.H.; Pennadam, S.; Alexander, C. Stimuli Responsive Polymers for Biomedical Applications. Chem. Soc. Rev. 2005, 34, 276-285. [CrossRef]

19. Dimitrov, I.; Trzebicka, B. Thermosensitive water-soluble copolymers with doubly responsive reversibly interacting entities. Prog. Polym. Sci. 2007, 32, 1275-1343. [CrossRef]

20. Hocine, S.; Li, M.-H. Thermoresponsive self-assembled polymer colloids in water. Soft Matter 2013, 9, 5839-5861. [CrossRef]

21. Schmaljohann, D. Thermo- and pH-responsive polymers in drug delivery. Adv. Drug Deliv. Rev. 2006, 58, 1655-1670. [CrossRef]

22. Klouda, L.; Mikos, A.G. Thermoresponsive hydrogels in biomedical applications. Eur. J. Pharm. Biopharm. 2008, 68, 34-45. [CrossRef] [PubMed]

23. Bawa, P.; Pillay, V.; Choonara, Y.E.; du Toit, L.C. Stimuli-responsive polymers and their applications in drug delivery. Biomed. Mater. 2009, 4, 022001. [CrossRef] [PubMed]

24. Stuart, M.A.C.; Huck, W.T.S.; Genzer, J.; Müller, M.; Ober, C.; Stamm, M.; Sukhorukov, G.B.; Szleifer, I.; Tsukruk, V.V.; Urban, M.; et al. Emerging applications of stimuli-responsive polymer materials. Nat. Mater. 2010, 9, 101-113. [CrossRef] [PubMed]

25. Ward, M.A.; Georgiou, T.K. Thermoresponsive Polymers for Biomedical Applications. Polymers 2011, 3, 1215-1242. [CrossRef]

26. Dong, J.; Wang, Y.; Zhang, J.; Zhan, X.; Zhu, S.; Yang, H.; Wang, G. Multiple stimuli-responsive polymeric micelles for controlled release. Soft Matter 2012, 9, 370-373. [CrossRef]

27. Kim, H.J.; Lee, J.H.; Lee, M. Stimuli-Responsive Gels from Reversible Coordination Polymers. Angew. Chem. Int. Ed. 2005, 44, 5810-5814. [CrossRef]

28. Mathew, A.P.; Cho, K.H.; Uthaman, S.; Cho, C.S.; Park, I.K. Stimuli-Regulated Smart Polymeric Systems for Gene Therapy. Polymers 2017, 9, 152. [CrossRef]

29. Kocak, G.; Tuncer, C.; Butun, V. pH-Responsive Polymers. Polym. Chem. 2017, 8, 144-176. [CrossRef] 
30. Gao, C.; Leporatti, S.; Moya, S.; Donath, E.; Möhwald, H. Swelling and Shrinking of Polyelectrolyte Microcapsules in Response to Changes in Temperature and Ionic Strength. Chem. Eur. J. 2003, 9, 915-920. [CrossRef]

31. Lee, A.S.; Bütün, V.; Vamvakaki, M.; Armes, S.P.; Pople, J.A.; Gast, A.P. Structure of pH-Dependent Block Copolymer Micelles: Charge and Ionic Strength Dependence. Macromolecules 2002, 35, 8540-8551. [CrossRef]

32. Roy, D.; Brooks, W.; Sumerlin, B. New directions in thermoresponsive polymers. Chem. Soc. Rev. 2013, 42, 7214-7243. [CrossRef] [PubMed]

33. Chikh Alard, I.; Soubhye, J.; Berger, G.; Gelbcke, M.; Spassov, S.; Amighi, K.; Goole, J.; Meyer, F. Triple-stimuli responsive polymers with fine tuneable magnetic responses. Polym. Chem. 2017, 8, 2450-2456. [CrossRef]

34. Baines, F.L.; Armes, S.P.; Billingham, N.C.; Tuzar, Z. Micellization of Poly(2-(dimethylamino)ethyl methacrylate-block-methyl methacrylate) Copolymers in Aqueous Solution. Macromolecules 1996, 29, 8151-8159. [CrossRef]

35. Niskanen, J.; Wu, C.; Ostrowski, M.; Fuller, G.G.; Hietala, S.; Tenhu, H. Thermoresponsiveness of PDMAEMA. Electrostatic and Stereochemical Effects. Macromolecules 2013, 46, 2331-2340. [CrossRef]

36. Maryam, M.; Mehdi, S.K.; Hossein, R.M.; Marzieh, G. Effect of molecular weight and polymer concentration on the triple temperature/ $\mathrm{pH}$ /ionic strength-sensitive behavior of poly(2-(dimethylamino)ethyl methacrylate). Int. J. Polym. Mater. 2016, 66, 455-461. [CrossRef]

37. Agarwal, S.; Zhang, Y.; Maji, S.; Greiner, A. PDMAEMA based gene delivery materials. Mater. Today 2012, 15, 388-393. [CrossRef]

38. Perrier, S. 50th Anniversary Perspective: RAFT Polymerization-A User Guide. Macromolecules 2017, 50, 7433-7447. [CrossRef]

39. Germack, D.; Wooley, K. RAFT-based synthesis and characterization of ABC vs. ACB triblock copolymers containing tert-butyl acrylate, isoprene and styrene blocks. Macromol. Chem. Phys. 2007, 208, 2481-2491. [CrossRef]

40. Moad, G. RAFT polymerization to form stimuli-responsive polymers. Polym. Chem. 2017, 8, 177-219. [CrossRef]

41. Moad, G.; Rizzardo, E.; Thang, S. Living Radical Polymerization by the RAFT Process-A First Update. Aust. J. Chem. 2006, 59, 669-692. [CrossRef]

42. Moad, G.; Rizzardo, E.; Thang, S.H. Living Radical Polymerization by the RAFT Process-A Second Update. Aust. J. Chem. 2009, 62, 1402-1472. [CrossRef]

43. Vuoriluoto, M.; Orelma, H.; Johansson, L.S.; Zhu, B.; Poutanen, M.; Walther, A.; Laine, J.; Rojas, O.J. Effect of Molecular Architecture of PDMAEMA-POEGMA Random and Block Copolymers on Their Adsorption on Regenerated and Anionic Nanocelluloses and Evidence of Interfacial Water Expulsion. J. Phys. Chem. B 2015, 119, 15275-15286. [CrossRef] [PubMed]

44. Manouras, T.; Koufakis, E.; Anastasiadis, S.H.; Vamvakaki, M. A facile route towards PDMAEMA homopolymer amphiphiles. Soft Matter 2017, 13, 3777-3782. [CrossRef] [PubMed]

45. Lowe, A.B.; McCormick, C.L. Synthesis and Solution Properties of Zwitterionic Polymers. Chem. Rev. 2002, 102, 4177-4190. [CrossRef] [PubMed]

46. Antoun, S.; Gohy, J.F.; Jérôme, R. Micellization of quaternized poly(2-(dimethylamino)ethyl methacrylate)-block-poly(methyl methacrylate) copolymers in water. Polymer 2001, 42, 3641-3648. [CrossRef]

47. Lutz, J.F. Polymerization of oligo(ethylene glycol) (meth)acrylates: Toward new generations of smart biocompatible materials. J. Polym. Sci. Part A Polym. Chem. 2008, 46, 3459-3470. [CrossRef]

48. Giaouzi, D.; Pispas, S. Effects of Chemical Modifications on the Thermoresponsive Behavior of a PDMAEA-b-PNIPAM-b-POEGA Triblock Terpolymer. Polymers 2020, 12, 1382. [CrossRef]

49. Koufakis, E.; Manouras, T.; Anastasiadis, S.H.; Vamvakaki, M. Film Properties and Antimicrobial Efficacy of Quaternized PDMAEMA Brushes: Short vs Long Alkyl Chain Length. Langmuir 2020, 36, 3482-3493. [CrossRef]

50. Bütün, V.; Armes, S.P.; Billingham, N.C. Selective Quaternization of 2-(Dimethylamino)ethyl Methacrylate Residues in Tertiary Amine Methacrylate Diblock Copolymers. Macromolecules 2001, 34, 1148-1159. [CrossRef]

51. Vamvakaki, M.; Unali, G.F.; Bütün, V.; Boucher, S.; Robinson, K.L.; Billingham, N.C.; Armes, S.P. Effect of Partial Quaternization on the Aqueous Solution Properties of Tertiary Amine-Based Polymeric Surfactants: Unexpected Separation of Surface Activity and Cloud Point Behavior. Macromolecules 2001, 34, 6839-6841. [CrossRef]

52. Chrysostomou, V.; Pispas, S. Stimuli-responsive amphiphilic PDMAEMA-b-PLMA copolymers and their cationic and zwitterionic analogs. J. Polym. Sci. Part A Polym. Chem. 2018, 56, 598-610. [CrossRef]

53. Skandalis, A.; Pispas, S. PDMAEMA-b-PLMA-b-POEGMA triblock terpolymers via RAFT polymerization and their self-assembly in aqueous solutions. Polym. Chem. 2017, 8, 4538-4547. [CrossRef]

54. Li, M.; Zhuang, B.; Yu, J. Functional Zwitterionic Polymers on Surface: Structures and Applications. Chem. Asian. J. 2020, 15, 2060-2075. [CrossRef] [PubMed]

55. Sugai, S.; Ebert, G. Conformations of hydrophobic polyelectrolytes. Advcolloid Interface Sci. 1986, 24, 247-282. [CrossRef]

56. Nalamachu, S.; Wortmann, R. Role of Indomethacin in Acute Pain and Inflammation Management:A Review of the Literature. Postgrad. Med. 2014, 126, 92-97. [CrossRef]

57. Frisken, B.J. Revisiting the method of cumulants for the analysis of dynamic light-scattering data. Appl. Opt. 2001, 40, 4087-4091. [CrossRef]

58. Rowe, R.A.; Pryse, K.; Elson, E.; Genin, G. Stable fitting of noisy stress relaxation data. Mech. Soft Mater. 2019, 1. [CrossRef]

59. Tavares, J.; Antunes, G.; Dias, C.; Gama, M.; Araujo, N. Smoluchowski equations for linker-mediated irreversible aggregation. Soft Matter 2020, 16. [CrossRef] 
60. Yañez-Macias, R.; Alvarez-Moises, I.; Perevyazko, I.; Lezov, A.; Guerrero-Santos, R.; Schubert, U.S.; Guerrero-Sanchez, C. Effect of the Degree of Quaternization and Molar Mass on the Cloud Point of Poly[2-(dimethylamino)ethyl methacrylate] Aqueous Solutions: A Systematic Investigation. Macromol. Chem. Phys. 2017, 218, 1700065. [CrossRef]

61. Ahrens, H.; Büscher, K.; Eck, D.; Förster, S.; Luap, C.; Papastavrou, G.; Schmitt, J.; Steitz, R.; Helm, C.A. Poly(styrene sulfonate) self-organization: Electrostatic and secondary interactions. Macromol. Symp. 2004, 211, 93-106. [CrossRef]

62. Song, K.; Lee, H.; Choung, I.; Cho, K.; Ahn, Y.; Choi, E. The effect of type of organic phase solvents on the particle size of poly(D,L-lactide-co-glycolide) nanoparticles. Colloids Surf. A Physichochem. Eng. Asp. 2006, 276, 162-167. [CrossRef]

63. Ohno, S.; Ishihara, K.; Yusa, S. Formation of Polyion Complex (PIC) Micelles and Vesicles with Anionic pH-Responsive Unimer Micelles and Cationic Diblock Copolymers in Water. Langmuir 2016, 32, 3945-3953. [CrossRef] [PubMed]

64. Du, J.; Lu, H. Polymeric Micelles. In Encyclopedia of Polymer Science and Technology, 4th ed.; Mark, H.F., Ed.; John Wiley \& Sons Inc.: Hoboken, NJ, USA, 2012.

65. Rodríguez-Laguna, N.; Reyes-García, L.I.; Moya-Hernández, R.; Rojas-Hernández, A.; Gómez-Balderas, R. Chemical Speciation of the System Cu(II)-Indomethacin in Ethanol and Water by UV-Vis Spectrophotometry. J. Chem. 2016, 2016, 1-12. [CrossRef]

66. Giaouzi, D.; Pispas, S. Synthesis and self-assembly of thermoresponsive poly(N-isopropylacrylamide)-b-poly(oligo ethylene glycol methyl ether acrylate) double hydrophilic block copolymers. J. Polym. Sci. Part A Polym. Chem. 2019, 57, 1467-1477. [CrossRef] 